Supporting Information for

\title{
Effects of Intramolecular Hydrogen-Bonding on the Fluorescence of PRODAN Derivatives
}

\author{
Isaac G. Alty, Douglas W. Cheek, Tao Chen, David B. Smith, Emma Q. Walhout and
}

Christopher J. Abelt*

Department of Chemistry, College of William and Mary, Williamsburg, VA 23185

General Information. NMR spectra were obtained with an Agilent DD2-400 or Varian Mercury VX-400 spectrometer. High resolution ESI-MS were acquired with a Bruker Apex-Qe instrument. All solvents were spectrophotometric grade. Fluorescence emission data were collected using a fiber optic system with a $366 \mathrm{~nm}$ LED light source and an Ocean Optics Maya CCD detector. Samples were thermostated at $23^{\circ} \mathrm{C}$. Absorption spectra were obtained from the same fiber optic system with a miniature deuterium/tungsten light source.

Absorption Data. Two solutions of identical concentrations of $\mathbf{1}$ - $\mathbf{3}$ were made by diluting 20 $\mu \mathrm{L}$ of a stock solution of $\mathbf{1}-\mathbf{3}(\sim 5 \mathrm{mg} / 10 \mathrm{~mL}$ toluene $)$ to $5 \mathrm{~mL}$ with the aprotic and protic solvents. Two series of data were acquired for each binary system. In the first set $2.0 \mathrm{~mL}$ of the aprotic solution was sequentially spiked with four aliquots of the protic solution, and the solution was stirred for thirty seconds before recording the intensity. In the second set, $2.0 \mathrm{~mL}$ of the alcohol solution was spiked with two aliquots of the aprotic solution. In this way the absorbances for a set of regularly-spaced binary mixtures $(0,10,20,40,60,80,90,100 \mathrm{~mol} \%)$ were determined. The best-fit third-order polynomial to the plot of normalized absorption vs. mole fraction was used to calculate the relative molar absorptivities for the solutions used in the fluorescence studies below. 
Fluorescence Data. Two solutions of identical concentrations of $\mathbf{1}$ - $\mathbf{3}$ in the aprotic and protic solvents were made by diluting $20 \mu \mathrm{L}$ of a stock solution of $\mathbf{1}-\mathbf{3}(\sim 5 \mathrm{mg} / 10 \mathrm{~mL}$ toluene) to $5 \mathrm{~mL}$. Two sets of emission data were acquired for each binary system. In the first set $2.0 \mathrm{~mL}$ of the toluene solution was sequentially spiked with nineteen-twenty two aliquots of the alcohol solution, and the solution was stirred for thirty seconds before recording the emission. In the second set, $2.0 \mathrm{~mL}$ of the alcohol solution was spiked with seven aliquots of the aprotic solution. The abscissa scale of the intensity $v s$. wavelength data was converted to wavenumbers before subsequent mathematical treatment. The electronic noise was subtracted from the raw emission intensity. The net intensity at each point was divided by the spectral response of the Hamamatsu S10420 CCD and multiplied by $\lambda^{2} / \lambda_{\max }{ }^{2}$ to account for the effect of the abscissa-scale conversion. ${ }^{1}$

Calculation of spectral values and fractional changes. For each fluorescence spectrum two sets of spectral values $(Y)$ were calculated: 1) the relative quantum yield, $Q_{\text {rel, }}$ and 2) the product of the center-of-mass and the relative quantum yield, $\tilde{v}_{\mathrm{CM}} \cdot Q_{\text {rel. }}{ }^{2}$ The integrated emission intensities $\left(I_{\text {int }}\right)$ were converted to relative quantum yields using equation $\mathrm{S} 1$ which takes into account changes in the relative molar absorptivities $(\varepsilon)$ and refractive indices $(\eta)$. The refractive indices of the toluene/methanol mixtures were available from the literature. ${ }^{3}$ The refractive indices of the

${ }^{1}$ Lakowicz, J., Principles of Fluorescence Spectroscopy; Kluwer Academic/Plenum Publishers: New York, 1999; Vol. 2.

${ }^{2}$ Zurawsky, W.P; Scarlata, S.F. Preferential Solvation of 6-Propionyl (N,N-Dimethylamino) Naphthalene in Binary, Polar Solvent Mixtures. J. Phys. Chem. 1992, 96, 6012-6016.

${ }^{3}$ Atik, Z. Experimental and Predicted Volumetric and Refractive Index Properties of Ternary Mixtures of Iodoethane with Toluene and Alcohols at Temperature 298.15 K and Pressure 101 kPa. J. Chem. Thermodyn. 2006, 38, 201-208. 
toluene/isopropanol mixtures were calculated using the Gladestone-Dale equation ${ }^{4}$ from the excess molar volume data for known solvent compositions. ${ }^{5}$ The refractive indices of the acetonitrile/methanol mixtures were calculated using the Gladestone-Dale equation using density data for known solvent compositions. ${ }^{6}$ Equation S2 was used to calculate the emission center-ofmass $\left(\tilde{v}_{\mathrm{CM}}\right)$ values. Fractional changes $(I)$ in the spectral values $(Y)$ were determined from equation S3 where $Y_{1}$ is the spectral value for the excited fluorophore in the aprotic solvent and $Y_{2}$ is the value in the protic solvent.

$$
\begin{gathered}
Q_{\text {rel }}=I_{\text {adj }} /\left(I_{\text {adj }}\right)_{\max } \quad \text { where } I_{\text {adj }}=I_{\text {int }} \cdot \frac{\varepsilon_{\text {max }}}{\varepsilon} \cdot \frac{\eta^{2}}{\eta_{\min }^{2}} \\
\tilde{v}_{\mathrm{CM}}=\frac{\int I(\tilde{v}) \cdot \tilde{v} d \tilde{v}}{\int I(\tilde{v}) d \tilde{v}}=\frac{\int I(\tilde{v}) \cdot \tilde{v} d \tilde{v}}{I_{\text {int }}} \\
\Gamma=\frac{Y_{1}-Y}{Y_{1}-Y_{2}}
\end{gathered}
$$

Preferential Solvation Model. The two-step exchange solvation model formulated by Rosés and Bosch is shown in equations S4 and S5 below. The equilibria invoke three solvated excited states

${ }^{4}$ Herráez, J.V.; Belda, R. Refractive Indices, Densities and Excess Molar Volumes of Monoalcohols + Water. J. Solution Chem. 2006, 35, 1315-1328.

${ }^{5}$ Singh, K.; Kalra, K.; Maken, S.; Yadav, B. Excess Volumes of 1-Propanol and 2-Propanol with Aromatic Hydrocarbons at 298.15 K. J. Chem. Eng. Data 1994, 39, 241-244.

${ }^{6}$ Nikam, P. S.; Shirsat, L. N.; Hasan, M. Density and Viscosity Studies of Binary Mixtures of Acetonitrile with Methanol, Ethanol, Propan-1-ol, Propan-2-ol, Butan-1-ol, 2-Methylpropan-1-ol, and 2-Methylpropan-2-ol at $(298.15,303.15,308.15$, and 313.15) K. J. Chem. Eng. Data 1998, $43,732-737$. 
$\left(F^{*}\right)$ : two surrounded by either aprotic or protic solvents and a third surrounded by mixture of the two. The equilibrium constants $f_{2 / 1}$ and $f_{12 / 1}$ are for double solvent exchange and single exchange, respectively.

$$
\begin{gathered}
F^{*}(\text { aprotic })_{2}+\text { protic } \stackrel{f_{12 / 1}}{\rightleftarrows} F^{*}(\text { aprotic, protic })+\text { aprotic } \\
F^{*}(\text { aprotic })_{2}+2 \text { protic } \stackrel{f_{2 / 1}}{\rightleftarrows} F^{*}(\text { protic })_{2}+2 \text { aprotic }
\end{gathered}
$$

The change in spectral value $(\Gamma)$ is related to the equilibrium constants and the mole fraction of the protic solvent through equation S6.

$$
\Gamma=\frac{Y_{1}-Y}{Y_{1}-Y_{2}}=\frac{f_{2 / 1} x^{2}+f_{12 / 1} r x(1-x)}{(1-x)^{2}+f_{2 / 1} x^{2}+f_{12 / 1} x(1-x)}
$$

Taking the difference between the two types of spectral values eliminates the second order term in the numerator (equation S7):

$$
\Gamma_{\mathrm{CM} \bullet \mathrm{Q}}-\Gamma_{\mathrm{Q}}=\frac{f_{12 / 1} \Delta r x(1-x)}{(1-x)^{2}+f_{2 / 1} x^{2}+f_{12 / 1} x(1-x)} \quad \text { where } \Delta r=r_{\mathrm{CM} \bullet \mathrm{Q}}-r_{\mathrm{Q}}
$$

The derivative of S7 with respect to mole fraction gives a quadratic term in the numerator (S8).

$$
\frac{d\left(\Gamma_{\mathrm{CM} \cdot \mathrm{Q}}-\Gamma_{\mathrm{Q}}\right)}{d x}=\frac{\left(x^{2}\left(1-f_{2 / 1}\right)-2 x+1\right) \times\left(f_{12 / 1} \Delta r\right)}{\left((1-x)^{2}+f_{2 / 1} x^{2}+f_{12 / 1} x(1-x)\right)^{2}}
$$

The difference function $\Gamma_{\mathrm{Q}}-\Gamma_{\mathrm{CM} \cdot \mathrm{Q}}$ has an extreme value when the first derivative is zero; specifically, when the quadratic term in the numerator is zero. The mole fraction where the maximum occurs is determined by fitting six points $\left(\left[\Gamma_{\mathrm{Q}}-\Gamma_{\mathrm{CM}} \cdot \mathrm{Q}\right] v s . \mathrm{x}\right)$ around the maximum to 
a third-order polynomial function, taking its derivative, setting it to zero and solving for the mole fraction. This mole fraction defines the value for $f_{2 / 1}$ through equation S9.

$$
f_{2 / 1}=\frac{1}{x^{2}}-\frac{2}{x}+1
$$

The remaining parameters $f_{12 / 1}$ and $r$ in equation $\mathrm{S} 6$ are determined through non-linear least squares fitting for both plots of $\Gamma_{\mathrm{CM} \cdot \mathrm{Q}}$ and $\Gamma_{\mathrm{Q}} v s$. mole fraction.

Synthesis of $1-3$.

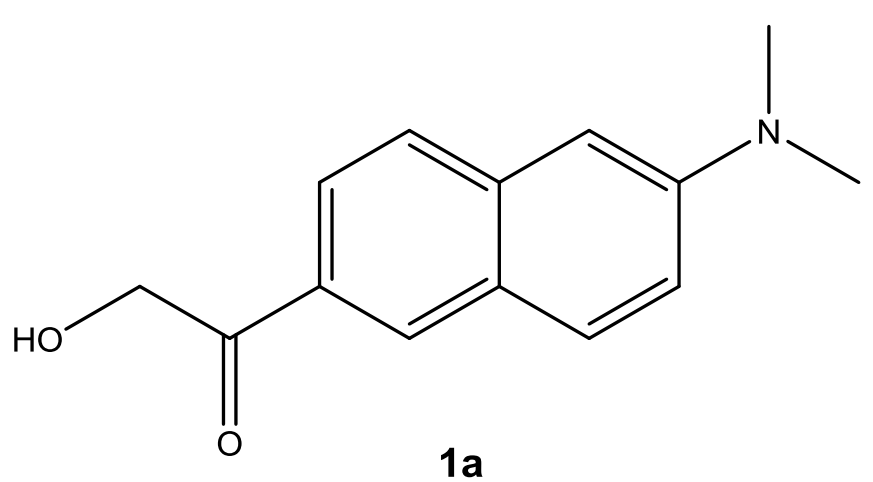

1-(6-(dimethylamino)naphthalen-2-yl)-2-hydroxyethan-1-one, 1a.

Preparation of the Weinreb amide. N-Methoxy-2-(methoxymethoxy)- $N$-methylacetamide was made by protecting 2-hydroxy- $N$-methoxy- $N$-methylacetamide with chloromethyl methyl ether using the method of Bachmann et.al. ${ }^{7}$ This alcohol was made by amidation of methyl glycolate with $\mathrm{N}, \mathrm{O}$-dimethylhydroxylamine using three equivalents of isopropyl magnesium chloride following the method of Trost et. al. ${ }^{8}$

${ }^{7}$ Bachmann, S.; Fettes, A.; Iding, H.;Wirz, B.; Zutter, U. Process for the preparation of a glucokinase activator compound. US 20110054174 A1 2011.

${ }^{8}$ Trost, B.M.; Miege, F. Development of ProPhenol Ligands for the Diastereo- and Enantioselective Synthesis of $\beta$-Hydroxy- $\alpha$-Amino Esters. J. Am. Chem. Soc. 2014, 136, 3016-3019. 
Preparation of the Prodan Derivative 1a. 6-Bromo- $N, N$-dimethylnaphthalen-2-amine ${ }^{9}$ (1.35 g, $5.4 \mathrm{mmol})$ was dissolved in dry THF $(40 \mathrm{~mL})$ and the solution was cooled to $-78^{\circ} \mathrm{C}$. A solution of $n$-BuLi (3.6 mL, 1.6 M in hexanes) was added dropwise, and the reaction was allowed to stir at $78^{\circ} \mathrm{C}$ for $30 \mathrm{~min}$. The Weinreb amide $(0.93 \mathrm{~g}, 5.7 \mathrm{mmol})$ was added dropwise. The reaction was allowed to warm slowly over $1.5 \mathrm{hrs}$. Water $(5 \mathrm{~mL})$ was added and the mixture was stirred overnight. Diethyl ether was added $(150 \mathrm{~mL})$ and the organic layer was washed three times with water $\left(100 \mathrm{~mL}\right.$ ea). The organic layer was dried over $\mathrm{MgSO}_{4}$ and concentrated in vacuo. The crude MOM-ether was hydrolyzed in $\mathrm{EtOH}(15 \mathrm{~mL})$ and $\mathrm{HCl}(5 \mathrm{ml}, 6 \mathbf{M})$ at $65^{\circ} \mathrm{C}$ for $2 \mathrm{hrs}$. The reaction was cooled, then poured into $2 \%$ aq. $\mathrm{Na}_{2} \mathrm{CO}_{3}(300 \mathrm{~mL})$. Salt was added $(\mathrm{NaCl}, 40 \mathrm{~g})$, the mixture was stirred, then filtered with suction. The filtrate was extracted three times with $\mathrm{CH}_{2} \mathrm{Cl}_{2}$ (100 $\mathrm{mL}$ ea), the organic layers were combined, dried over $\mathrm{CaCl}_{2}$, and concentrated in vacuo. The crude product was chromatographed on silica get using EtOAc/hexanes ( $0 \%$ to $50 \%)$ affording $170 \mathrm{mg}$ (14\%, two steps) of 1-(6-(dimethylamino)naphthalen-2-yl)-2-hydroxyethan-1-one as a tan solid after sublimation under vacuum, m.p. $158-160^{\circ} \mathrm{C} .{ }^{1} \mathrm{H}$ NMR $\left(400 \mathrm{MHz}, \mathrm{CDCl}_{3}\right) \delta 8.26(\mathrm{~d}$, $J=1.7,1 \mathrm{H}), 7.86(\mathrm{dd}, J=8.6,1.7 \mathrm{~Hz}, 1 \mathrm{H}), 7.80(\mathrm{~d}, J=9.2 \mathrm{~Hz}, 1 \mathrm{H}) 7.66(\mathrm{~d}, J=8.6,1 \mathrm{H}), 7.18(\mathrm{dd}$, $J=9.2,2.6 \mathrm{~Hz}, 1 \mathrm{H}), 6.86(\mathrm{~d}, J=2.6 \mathrm{~Hz}, 1 \mathrm{H}), 4.96$ (br. d, $J=2.6 \mathrm{~Hz}, 2 \mathrm{H}) 3.13(\mathrm{~s}, 6 \mathrm{H}) .{ }^{13} \mathrm{C}$ NMR (100 MHz, CDCl3) $\delta 40.59,65.31,105.4,116.64,123.96,125.05,126.73,126.79,129.92,131.06$, 138.54, 150.77, 197.62. HRMS (ESI): calcd. for $\mathrm{C}_{14} \mathrm{H}_{15} \mathrm{NO}_{2} \mathrm{Na}^{+}[\mathrm{M}+\mathrm{Na}]^{+}$252.09950; found 252.09960.

${ }^{9}$ Silvonek, S.S.; Giller, C.G.; Abelt, C.J. Alternate Syntheses of Prodan and Acrylodan. Org. Prep. Proced. Int. 2005, 37, 589-594. 


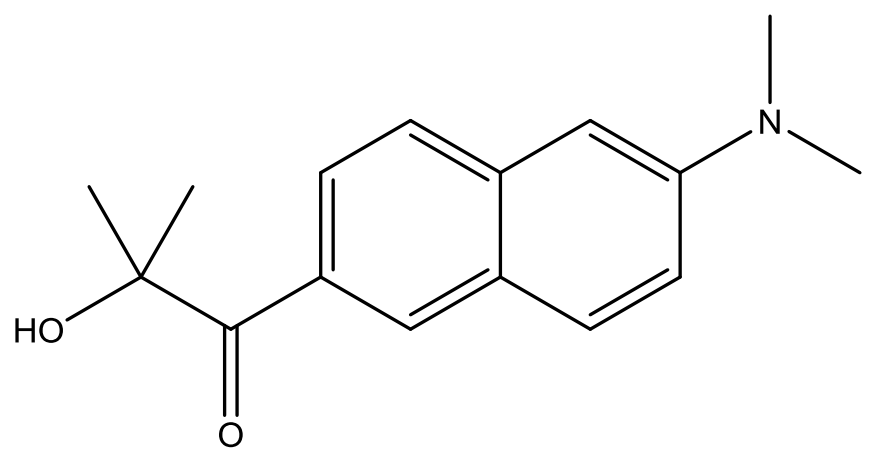

2a

1-(6-(dimethylamino)naphthalen-2-yl)-2-hydroxy-2-methylpropan-1-one, 2 a.

Preparation of the Weinreb amide. $\quad N$-methoxy-2-(methoxymethoxy)- $N, 2-$ dimethylpropanamide ${ }^{8}$ was made by protecting 2 -hydroxy- $N$-methoxy- $N$-methylacetamide with chloromethyl methyl ether using the method of Bachmann et.al. ${ }^{7}$ This alcohol was made by amidation of methyl 2-hydroxy-2-methylpropanoate with $\mathrm{N}, \mathrm{O}$-dimethylhydroxylamine using three equivalents of isopropyl magnesium chloride following the method of Trost et. al. ${ }^{8}$

Preparation of the Prodan Derivative 2a. A solution of 6-bromo- $N, N$-dimethylnaphthalen-2amine ( $1.35 \mathrm{~g}, 5.4 \mathrm{mmol}$, sublimed just before use) in THF $(40 \mathrm{~mL})$ was cooled to $-78{ }^{\circ} \mathrm{C}$ under $\mathrm{N}_{2}$. A solution of $n$-BuLi (3.6 mL, 1.6 M in hexanes) was added dropwise with stirring. After stirring for 30 minutes at $-78{ }^{\circ} \mathrm{C}$ a mixture of $N$-methoxy-2-(methoxymethoxy)- $N, 2-$ dimethylpropanamide $(1.09 \mathrm{~g}, 5.68 \mathrm{mmol})$ in THF $(5 \mathrm{~mL})$ was added dropwise. The reaction was stirred for $1.5 \mathrm{hr}$ and allowed to warm slowly. Water $(100 \mathrm{~mL})$ was added, and the mixture was extracted with $\mathrm{CH}_{2} \mathrm{Cl}_{2}(2 \times 75 \mathrm{~mL})$. The combined organic layers were dried over $\mathrm{CaCl}_{2}$, and the solvent was removed in vacuo. The residue was suspended in EtOH $(15 \mathrm{~mL})$, aq. $\mathrm{HCl}(5 \mathrm{~mL}, 6$ N) was added, and the solution was warmed to $60-65^{\circ} \mathrm{C}$ for $2 \mathrm{hr}$. Water $(100 \mathrm{~mL})$ was added, and the aq. layer was extracted with $\mathrm{CH}_{2} \mathrm{Cl}_{2}(2 \times 75 \mathrm{~mL})$. The combined organic layers were dried 
over $\mathrm{CaCl}_{2}$ and concentrated in vacuo. The residue was chromatographed on silica gel using EtOAc/hexanes $\quad(0 \%$ to $50 \%)$ affording $250 \quad \mathrm{mg} \quad(15 \%$, two steps $)$ of $1-(6-$ (dimethylamino)naphthalen-2-yl)-2-hydroxy-2-methylpropan-1-one as an off-white solid after vacuum sublimation, m.p. $125-126^{\circ} \mathrm{C} .{ }^{1} \mathrm{H}$ NMR $\left(400 \mathrm{MHz}, \mathrm{CDCl}_{3}\right) \delta 8.46(\mathrm{~d}, J=1.8,1 \mathrm{H}), 7.98$ $(\mathrm{dd}, J=8.8,2.0 \mathrm{~Hz}, 1 \mathrm{H}), 7.80(\mathrm{~d}, J=9.2 \mathrm{~Hz}, 1 \mathrm{H}) 7.64(\mathrm{~d}, J=8.8,1 \mathrm{H}), 7.18(\mathrm{dd}, J=9.2,2.6 \mathrm{~Hz}, 1 \mathrm{H})$, $6.86(\mathrm{~d}, J=2.6 \mathrm{~Hz}, 1 \mathrm{H}), 3.12(\mathrm{~s}, 6 \mathrm{H}), 1.73(\mathrm{~s}, 6 \mathrm{H}) .{ }^{13} \mathrm{C} \mathrm{NMR}(100 \mathrm{MHz}, \mathrm{CDCl} 3) \delta 29.19,40.61$, 105.21, 116.50, 124.94, 126.17, 126.19, 126.37, 131.19, 132.31, 137.77, 150.71, 203.65. HRMS (ESI): calcd. for $\mathrm{C}_{16} \mathrm{H}_{19} \mathrm{NO}_{2} \mathrm{Na}^{+}[\mathrm{M}+\mathrm{Na}]^{+}$280.13080; found 280.13089 .

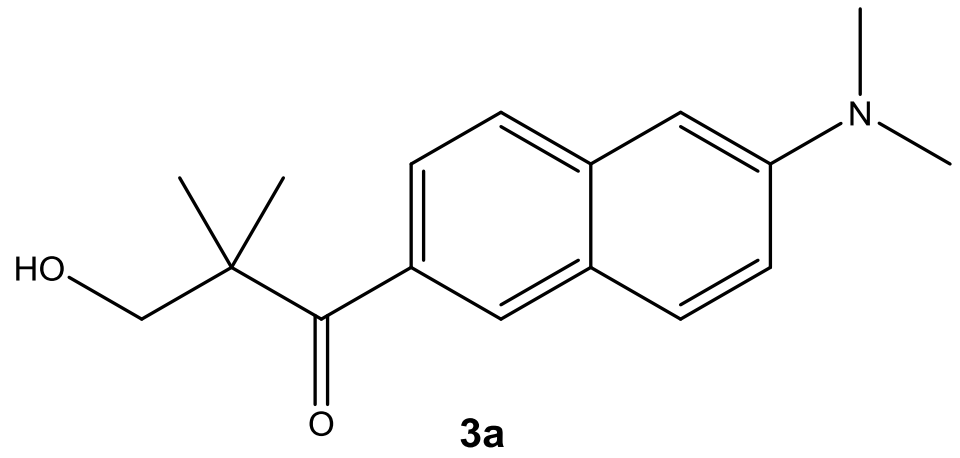

1-(6-(dimethylamino)naphthalen-2-yl)-3-hydroxy-2,2-dimethylpropan-1-one, $3 \mathbf{a}$.

Preparation of the Weinreb amide. To a solution of methyl 2-hydroxy-2-methylpropanoate (1.98 g, $15 \mathrm{mmol})$ in THF $(50 \mathrm{~mL})$ under $\mathrm{N}_{2}$ was added $N, O$-methylhydroxylamine hydrochloride $(2.20 \mathrm{~g}, 22.5 \mathrm{mmol})$. After cooling the solution to $-20^{\circ} \mathrm{C}$, a $2.0 \mathrm{M}$ solution of $i \mathrm{PrMgCl}$ in $\mathrm{THF}(30$ $\mathrm{mL}, 60 \mathrm{mmol}$ ) was added dropwise. The solution was allowed to warm to room temperature with stirring over $1.5 \mathrm{hr}$. The reaction was quenched with $\mathrm{H}_{2} \mathrm{O}(150 \mathrm{~mL})$. The mixture was extracted twice with $\mathrm{CH}_{2} \mathrm{Cl}_{2}$ (75 mL ea). The combined organic layers were dried over $\mathrm{CaCl}_{2}$ and concentrated in vacuo giving 3-hydroxy- $N$-methyoxy- $N$,2,2-trimethylpropanamide (1.13 g, 7.00 
mmol). This material was dissolved in $\mathrm{CH}_{2} \mathrm{Cl}_{2}(50 \mathrm{~mL})$ under $\mathrm{N}_{2}$, diisopropylethylamine (1.06 g, $8.22 \mathrm{mmol}$ ) was added followed by chloromethyl methyl ether $(850 \mathrm{mg}, 10.7 \mathrm{mmol})$. The reaction was stirred for $8 \mathrm{hrs}$ after which diisopropylethylamine (1.06 g, $8.22 \mathrm{mmol})$ and chloromethyl methyl ether $(850 \mathrm{mg}, 10.7 \mathrm{mmol})$ were added. The reaction was stirred for another $8 \mathrm{hr}$, then quenched with $\mathrm{H}_{2} \mathrm{O}(150 \mathrm{~mL})$. The mixture was extracted twice with $\mathrm{CH}_{2} \mathrm{Cl}_{2}(75 \mathrm{~mL}$ ea). The combined organic layers were dried over $\mathrm{CaCl}_{2}$ and concentrated in vacuo, and the crude amide was distilled under vacuum (b.p. $185^{\circ} \mathrm{C}, 0.1$ Torr).

Preparation of the Prodan Derivative 3a. A solution of 6-bromo- $N, N$-dimethylnaphthalen-2amine (1.35 g, $5.4 \mathrm{mmol}$, sublimed just before use) in THF $(40 \mathrm{~mL})$ was cooled to $-78^{\circ} \mathrm{C}$ under $\mathrm{N}_{2}$. A solution of $n$-BuLi (3.6 mL, 1.6 M in hexanes) was added dropwise with stirring. After stirring for 30 minutes at $-78{ }^{\circ} \mathrm{C}$ a mixture of $N$-methoxy-3-(methoxymethoxy)- $N, 2,2-$ trimethylpropanamide $(1.17 \mathrm{~g}, 5.68 \mathrm{mmol})$ in THF $(5 \mathrm{~mL})$ was added dropwise. The reaction was stirred for $1.5 \mathrm{hr}$ and allowed to warm slowly. Water $(100 \mathrm{~mL})$ was added, and the mixture was extracted with $\mathrm{CH}_{2} \mathrm{Cl}_{2}(2 \times 75 \mathrm{~mL})$. The combined organic layers were dried over $\mathrm{CaCl}_{2}$, and the solvent was removed in vacuo giving crude 1-(6-(dimethylamino)naphthalen-2-yl)-3(methoxymethoxy)-2,2-dimethylpropan-1-one (1.58 g, $5.00 \mathrm{mmol})$. This material was dissolved in $\mathrm{EtOH}(15 \mathrm{~mL})$, aq. $\mathrm{HCl}(5 \mathrm{~mL}, 6 \mathrm{~N})$ was added, and the solution was warmed to $60-65^{\circ} \mathrm{C}$ for 2 hr. Water $(100 \mathrm{~mL})$ was added, and the aq. layer was extracted with $\mathrm{CH}_{2} \mathrm{Cl}_{2}(2 \times 75 \mathrm{~mL})$. The combined organic layers were dried over $\mathrm{CaCl}_{2}$ and concentrated in vacuo. The crude product was chromatographed on silica get using EtOAc/hexanes (0\% to 50\%) affording $100 \mathrm{mg}$ (6\%, two steps) of 1-(6-(dimethylamino)naphthalen-2-yl)-3-hydroxy-2,2-dimethylpropan-1-one as a yellow-white solid after vacuum sublimation, m.p. $122-123^{\circ} \mathrm{C} .{ }^{1} \mathrm{H}$ NMR $\left(400 \mathrm{MHz}, \mathrm{CDCl}_{3}\right) \delta$ $8.30(\mathrm{~d}, J=1.8 \mathrm{~Hz}, 1 \mathrm{H}), 7.85(\mathrm{dd}, J=8.8,1.8 \mathrm{~Hz}, 1 \mathrm{H}), 7.77(\mathrm{~d}, J=9.2,1 \mathrm{H}), 7.62(\mathrm{~d}, J=8.8 \mathrm{~Hz}, 1 \mathrm{H})$, 
7.17 (dd, $J=9.2,2.4 \mathrm{~Hz}, 1 \mathrm{H}), 6.86(\mathrm{~d}, J=2.4 \mathrm{~Hz}, 1 \mathrm{H}), 3.70$ (br s, 2H), $3.11(\mathrm{~s}, 6 \mathrm{H}), 1.51$ (s, 6H); ${ }^{13} \mathrm{C}$ NMR $\left(100 \mathrm{MHz}, \mathrm{CDCl}_{3}\right) \delta$ 207.68, 150.18, 136.99, 130.63, 130.37, 129.77, 125.77, 125.68, 124.84, 116.33, 105.17, 71.63, 48.54, 40.44, 23.44. HRMS (ESI): calcd. for $\mathrm{C}_{17} \mathrm{H}_{21} \mathrm{NO}_{2} \mathrm{Na}^{+}$ $[\mathrm{M}+\mathrm{Na}]^{+} 294.14645$; found 280.14666 .

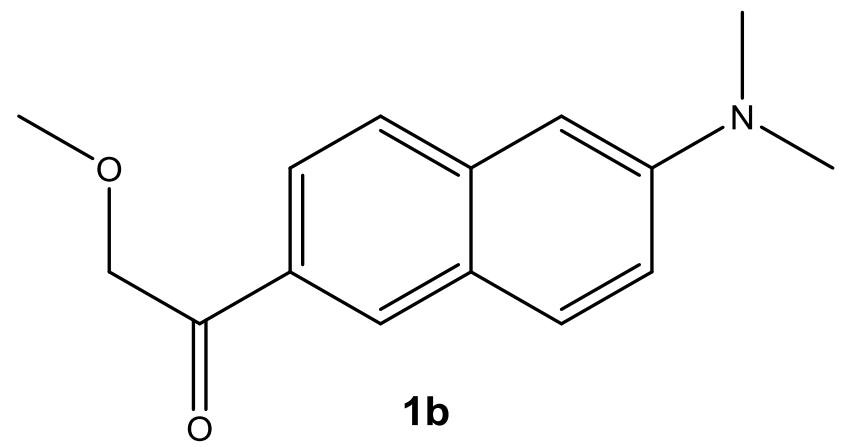

1-(6-(dimethylamino)naphthalen-2-yl)-2-methoxyethan-1-one, $\mathbf{1 b .}$

A solution of 6-bromo- $N, N$-dimethylnaphthalen-2-amine $(1.05 \mathrm{~g}, 4.2 \mathrm{mmol}$, sublimed just before use) in dry THF $(25 \mathrm{~mL})$ was cooled to $-78^{\circ} \mathrm{C}$ under $\mathrm{N}_{2} . n-\mathrm{BuLi}(3.0 \mathrm{~mL}, 1.6 \mathrm{M}$ in hexanes, $4.8 \mathrm{mmol}$ ) was added slowly dropwise, and the reaction was stirred for 30 min after addition was complete. Methyl 2-methoxyacetate $(1.3 \mathrm{~g}, 12.5 \mathrm{mmol})$ was added in one portion, and the reaction was stirred and allowed to warm to $-40^{\circ} \mathrm{C}$. The reaction was quenched with sat. aq. $\mathrm{NH}_{4} \mathrm{Cl}(3 \mathrm{~mL})$, and the solvent was allowed to evaporate over several days. The residue was ground together with silica gel and chromatographed on silica gel using EtOAc/hexanes ( $0 \%$ to $80 \%)$. Fractions containing the product were combined and sublimed under vacuum at $160^{\circ} \mathrm{C}$ affording $1-(6-$ (dimethylamino)naphthalen-2-yl)-2-methoxyethan-1-one (180 mg, 18\%), m.p. 97-98 ${ }^{\circ} \mathrm{C} .{ }^{1} \mathrm{H}$ NMR $\left(400 \mathrm{MHz}, \mathrm{CDCl}_{3}\right) \delta 8.31(\mathrm{~d}, J=1.6,1 \mathrm{H}), 7.89(\mathrm{dd}, J=8.7,1.6 \mathrm{~Hz}, 1 \mathrm{H}), 7.79(\mathrm{~d}, J=9.2,1 \mathrm{H}), 7.64$ (d, $J=8.7 \mathrm{~Hz}, 1 \mathrm{H}), 7.17(\mathrm{dd}, J=9.2,2.5 \mathrm{~Hz}, 1 \mathrm{H}), 6.87(\mathrm{~d}, J=2.5 \mathrm{~Hz}, 1 \mathrm{H}), 4.80(\mathrm{~s}, 2 \mathrm{H}) 3.54(\mathrm{~s}, 3 \mathrm{H})$, 3.12 (s, $6 \mathrm{H}) ;{ }^{13} \mathrm{C}$ NMR $\left(100 \mathrm{MHz}, \mathrm{CDCl}_{3}\right) \delta$ 195.43, 150.35, 137.91, 130.75, 129.67, 128.24, 
$126.30,124.92,124.12,116.32,105.25,75.24,59.45,40.41$; HRMS (ESI): calcd. for $\mathrm{C}_{15} \mathrm{H}_{17} \mathrm{NO}_{2} \mathrm{Na}^{+}[\mathrm{M}+\mathrm{Na}]^{+}$266.11515; found 266.11511.

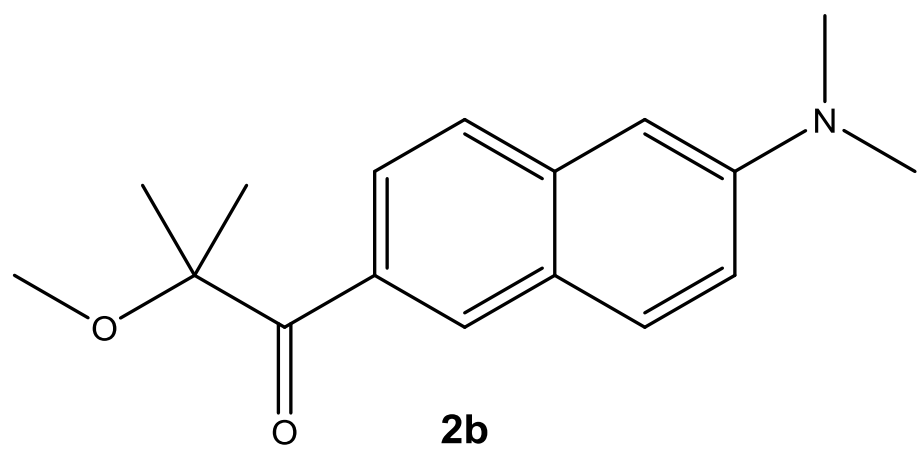

1-(6-(dimethylamino)naphthalen-2-yl)-2-methoxy-2-methylpropan-1-one, $2 \mathbf{b}$.

A solution of 6-bromo- $N, N$-dimethylnaphthalen-2-amine $(1.46 \mathrm{~g}, 5.6 \mathrm{mmol}$, sublimed just before use) in THF $(40 \mathrm{~mL})$ was cooled to $-78{ }^{\circ} \mathrm{C}$ under $\mathrm{N}_{2}$. A solution of $n$-BuLi (5.0 mL, 1.6 $\mathrm{M}$ in hexanes) was added dropwise with stirring. After stirring for 15 minutes at $-78{ }^{\circ} \mathrm{C}$ ethyl 2 methoxy-2-methylpropanoate $(2.0 \mathrm{~g}, 13.4 \mathrm{mmol})$ was added in one portion. The reaction was stirred for $1.5 \mathrm{hr}$ and allowed to warm slowly. Saturated ammonium chloride was added (100 mL), and the mixture was extracted with EtOAc $(2 \times 75 \mathrm{~mL})$. The combined organic layers were dried over $\mathrm{Na}_{2} \mathrm{SO}_{4}$, and the solvent was removed in vacuo. The crude product was purified by column chromatography (EtOAc/hexanes) followed by vacuum sublimation giving $0770 \mathrm{mg}$ (51\%), m.p. 114-115 ${ }^{\circ} \mathrm{C} .{ }^{1} \mathrm{H}$ NMR $\left(400 \mathrm{MHz}, \mathrm{CDCl}_{3}\right) \delta 8.84(\mathrm{~d}, J=1.6,1 \mathrm{H}), 8.15(\mathrm{dd}, J=9.0,1.6 \mathrm{~Hz}, 1 \mathrm{H}), 7.82$ (d, $J=9.0 \mathrm{~Hz}, 1 \mathrm{H}) 7.62(\mathrm{~d}, J=9.0,1 \mathrm{H}), 7.16(\mathrm{dd}, J=9.0,2.6 \mathrm{~Hz}, 1 \mathrm{H}), 6.86(\mathrm{~d}, J=2.6 \mathrm{~Hz}, 1 \mathrm{H}), 3.12$ (s, 6H), $1.73(\mathrm{~s}, 6 \mathrm{H}) .{ }^{13} \mathrm{C} \mathrm{NMR}\left(100 \mathrm{MHz}, \mathrm{CDCl}_{3}\right) \delta 25.14,40.46,52.58,83.66,105.19,116.02$, 
$125.11,125.72,126.22,128.10,131.11,131.86,137.48,150.30,202.84$. HRMS (ESI): calcd. for $\mathrm{C}_{17} \mathrm{H}_{21} \mathrm{NO}_{2} \mathrm{Na}^{+}[\mathrm{M}+\mathrm{Na}]^{+}$294.14645; found 294.14639.

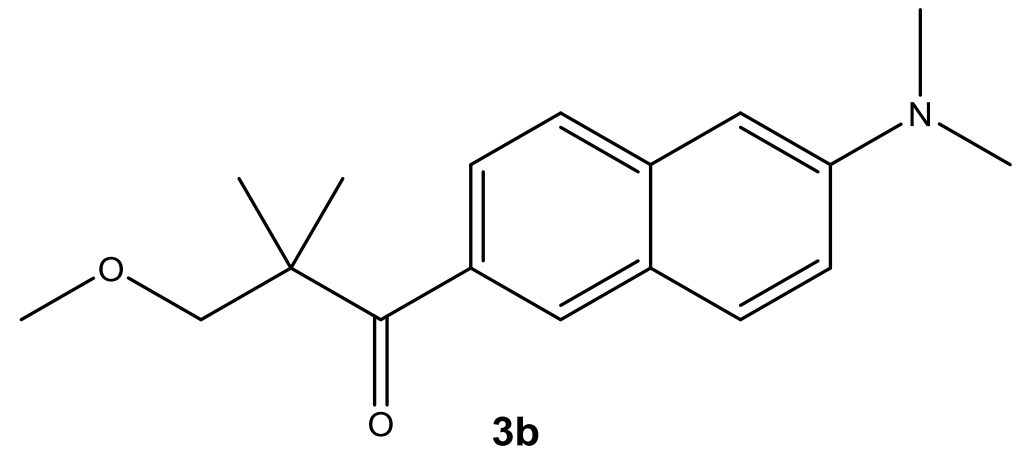

1-(6-(dimethylamino)naphthalen-2-yl)-3-methoxy-2,2-dimethylpropan-1-one, 3b.

A solution of 6-bromo- $N, N$ - dimethylnaphthalen-2-amine $(940 \mathrm{mg}, 3.8 \mathrm{mmol}$, sublimed just before use $)$ in dry THF $(25 \mathrm{~mL})$ was cooled to $-78^{\circ} \mathrm{C}$ under $\mathrm{N}_{2}$. A solution of $n-\mathrm{BuLi}(2.6 \mathrm{~mL}, 1.6$ $\mathrm{M}$ in hexanes, $4.2 \mathrm{mmol}$ ) was added slowly dropwise, and the reaction was stirred for $30 \mathrm{~min}$ after addition was complete. Methyl 3-methoxy-2,2-dimethylpropanoate (1.95 g, $13.3 \mathrm{mmol})$ was added in one portion, and the reaction was stirred and allowed to warm to $-40^{\circ} \mathrm{C}$. The reaction was quenched with sat. aq. $\mathrm{NH}_{4} \mathrm{Cl}(3 \mathrm{~mL})$, and the solvent was allowed to evaporate over several days. The residue was ground together with silica gel and chromatographed on silica gel using EtOAC/hexanes ( $0 \%$ to $80 \%)$. Fractions containing the product were allowed to evaporate slowly inducing crystallization. The crystals were collected and sublimed under vacuum affording 1-(6(dimethylamino)naphthalen-2-yl)-3-methoxy-2,2-dimethylpropan-1-one (300 mg, 28\%), m.p. 78$79^{\circ} \mathrm{C} .{ }^{1} \mathrm{H}$ NMR $\left(400 \mathrm{MHz}, \mathrm{CDCl}_{3}\right) \delta 8.15(\mathrm{~d}, J=1.7 \mathrm{~Hz} 1 \mathrm{H}), 7.76(\mathrm{~d}, J=8.4 \mathrm{~Hz}, 1 \mathrm{H}), 7.74(\mathrm{dd}$, $J=8.4,1.7 \mathrm{~Hz}, 1 \mathrm{H}), 7.61(\mathrm{~d}, J=8.9 \mathrm{~Hz}, 1 \mathrm{H}), 7.17(\mathrm{dd}, J=8.9,2.6 \mathrm{~Hz}, 1 \mathrm{H}), 6.88(\mathrm{~d}, J=2.6 \mathrm{~Hz}, 1 \mathrm{H})$ $3.61(\mathrm{~s}, 2 \mathrm{H}) 3.32(\mathrm{~s}, 3 \mathrm{H}), 3.09$ (s, 6H), $1.42(\mathrm{~s}, 6 \mathrm{H}) ;{ }^{13} \mathrm{C} \mathrm{NMR}\left(100 \mathrm{MHz}, \mathrm{CDCl}_{3}\right) \delta 207.04,150.00$, 
$136.56,131.95,130.48,129.00,125.81,125.75,125.23,116.54,105.60,80.50,59.49,48.90$, 40.77, 24.03; HRMS (ESI): calcd. for $\mathrm{C}_{18} \mathrm{H}_{23} \mathrm{NO}_{2} \mathrm{Na}^{+}[\mathrm{M}+\mathrm{Na}]^{+}$308.16210; found 308.16201.

\section{$\underline{\text { Solvatochromism Plots. }}$}

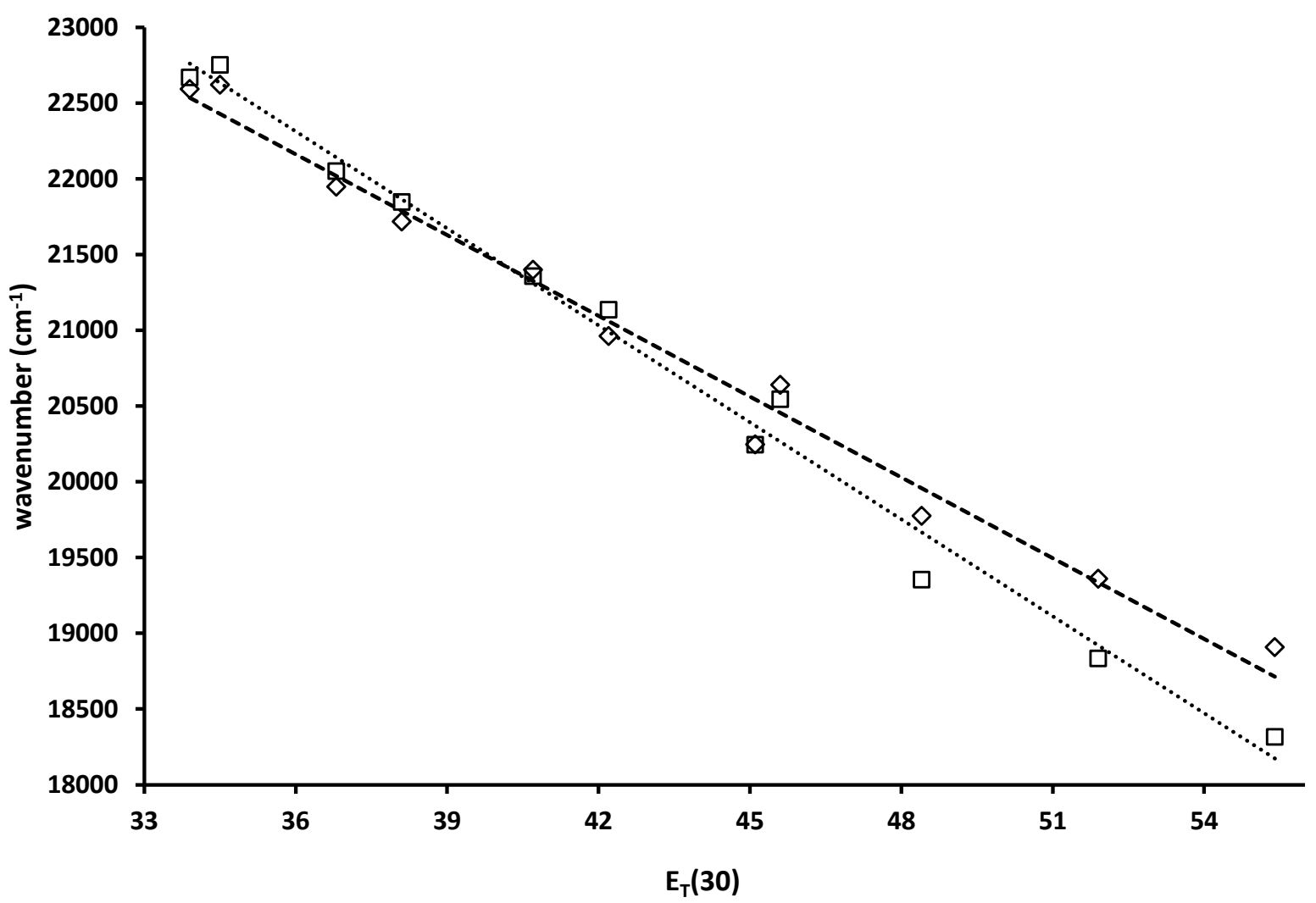

Figure S1. Plot of $\tilde{v}_{\mathrm{CM}} v s . \mathrm{E}_{\mathrm{T}}(30)$ for $\mathbf{1 a}(\vartheta,---)$ and $\mathbf{1 b}(\square, \cdots)$. Solvents are toluene, chlorobenzene, ethyl ether, methylene chloride, ethyl acetate, acetone, dimethyl sulfoxide, acetonitrile, isopropanol, ethanol and methanol. 


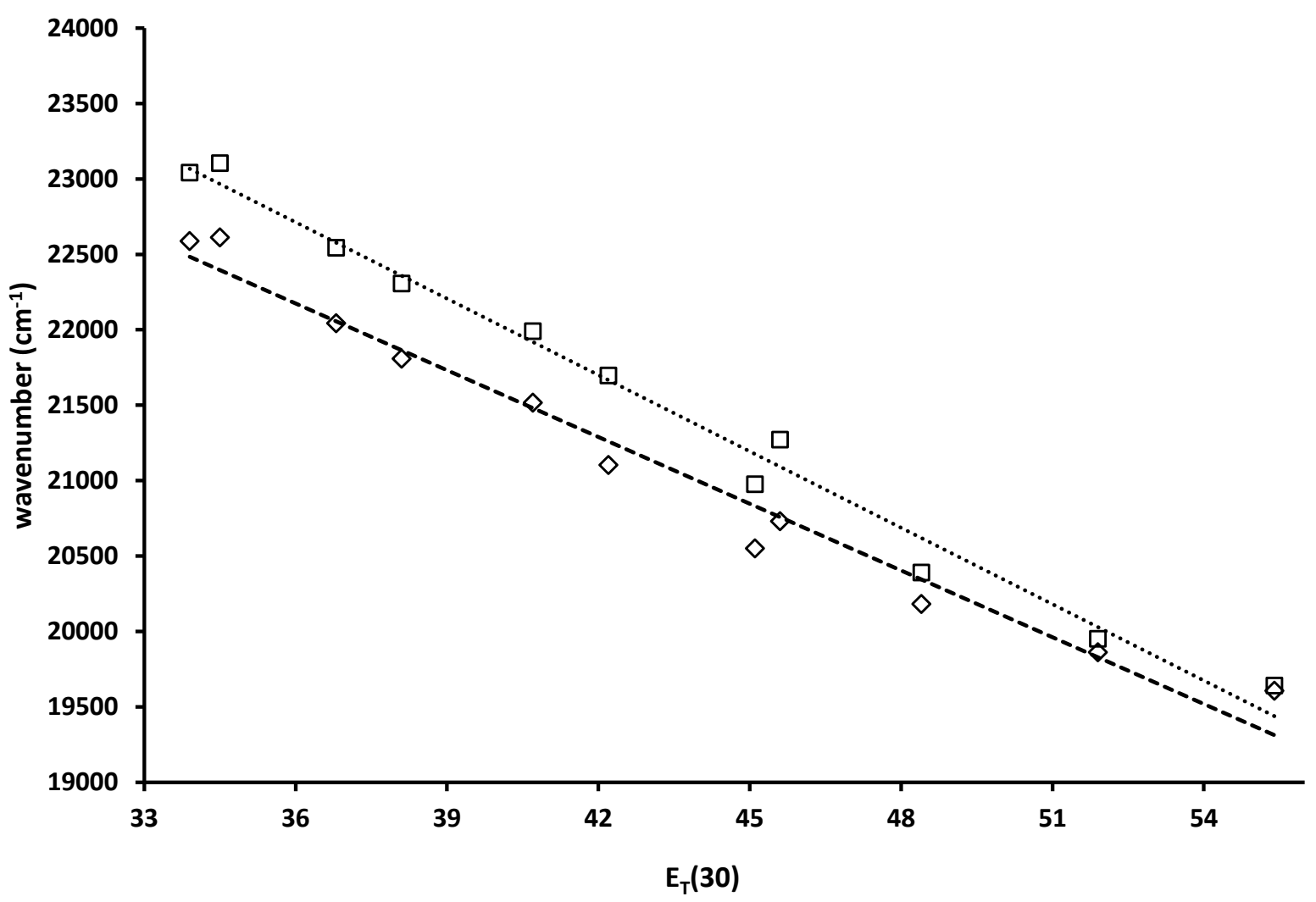

Figure S2. Plot of $\tilde{v}_{\mathrm{CM}} v s$. $\mathrm{E}_{\mathrm{T}}(30)$ for $\mathbf{3 a}(\diamond,--)$ and $\mathbf{3 b}(\square, \cdots)$. Solvents are toluene, chlorobenzene, ethyl ether, methylene chloride, ethyl acetate, acetone, dimethyl sulfoxide, acetonitrile, isopropanol, ethanol and methanol. 
Fluorescence Titrations.

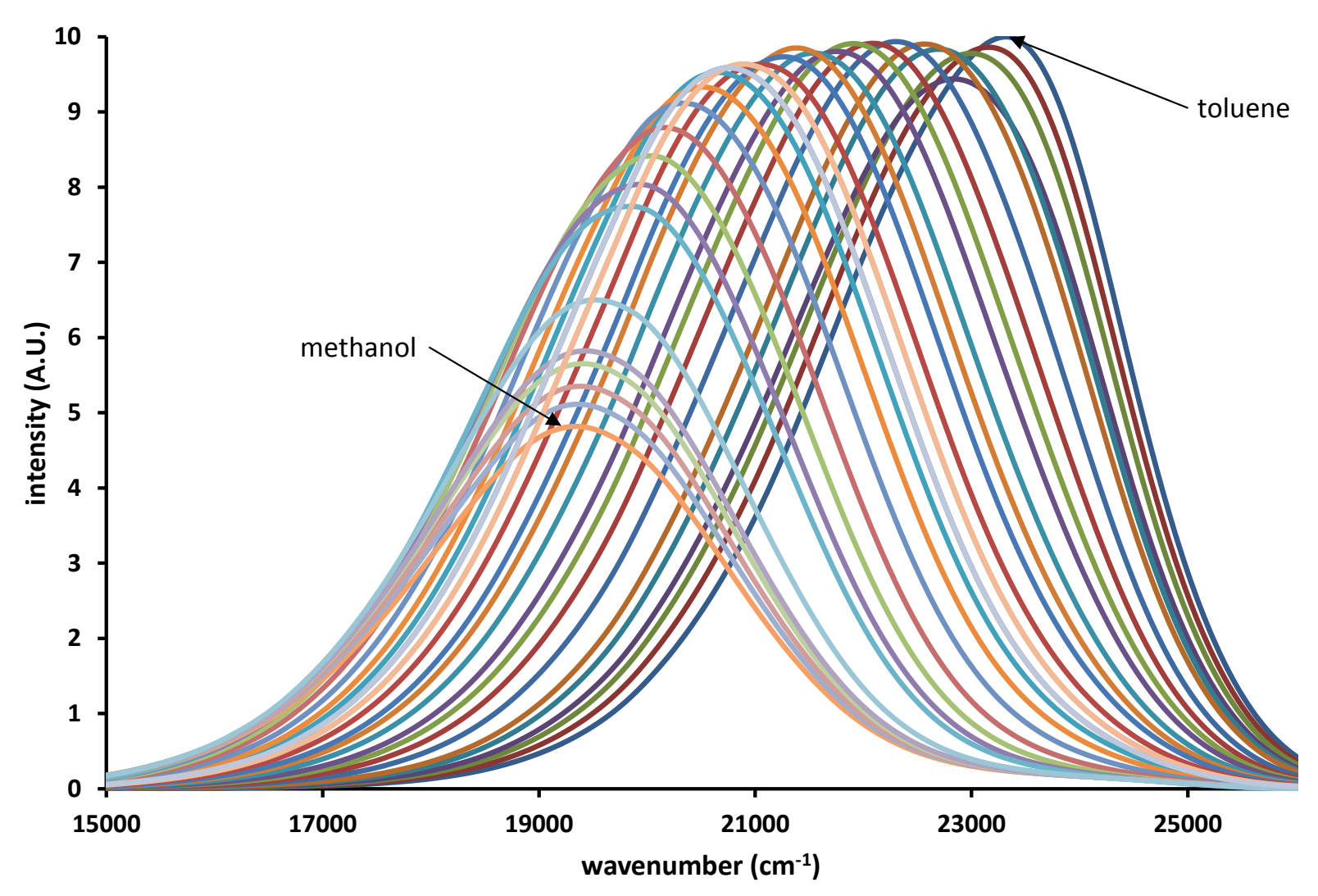

Figure S3. Fluorescence spectra of $6.8 \mu \mathrm{M}$ solutions of $1 \mathbf{a}$ in toluene/methanol mixtures. [MeOH] (mole \%): 0, 0.3, 0.5, 0.8, 1.0, 1.3, 1.9, 2.6, 3.2, 3.8, 5.0, 6.2 , 7.3, 9.5, 12, 14, 16, 21, 28, 40, 51, $61,68,77,81,87,93,95,96,98,100 . \lambda_{\mathrm{ex}}=366 \mathrm{~nm}$. 


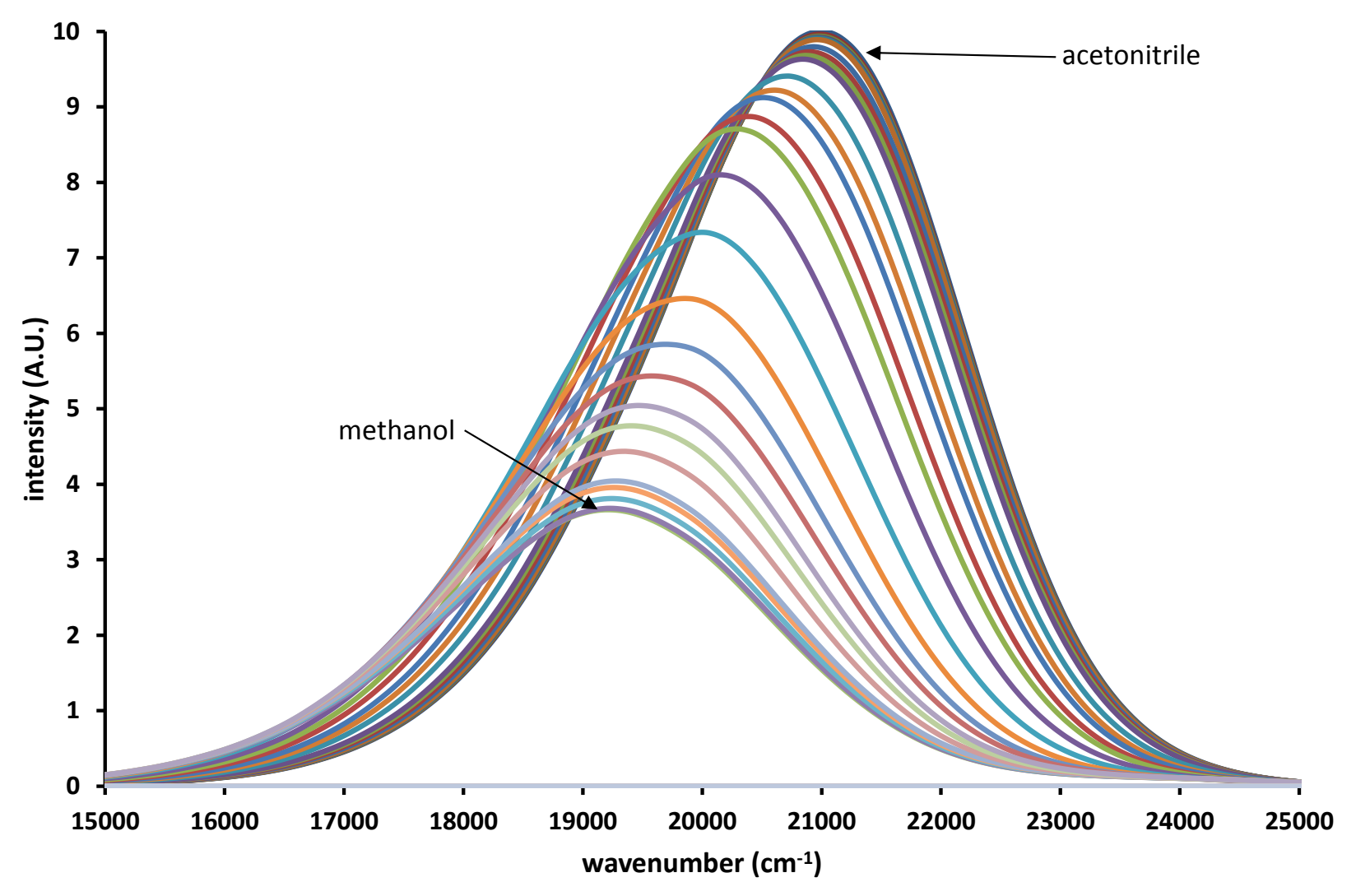

Figure S4. Fluorescence spectra of $6.8 \mu \mathrm{M}$ solutions of $1 \mathrm{a}$ in acetonitrile/methanol mixtures. $[\mathrm{MeOH}](\mathrm{mole} \%): 0,0.06,0.13,0.19,0.26,0.32,0.64,1.0,1.3,1.6,3.1,4.6,6.1,8.8,11,16,24$, $34,44,51,62,68,76,87,90,93,96,100 . \lambda_{\text {ex }}=366 \mathrm{~nm}$. 


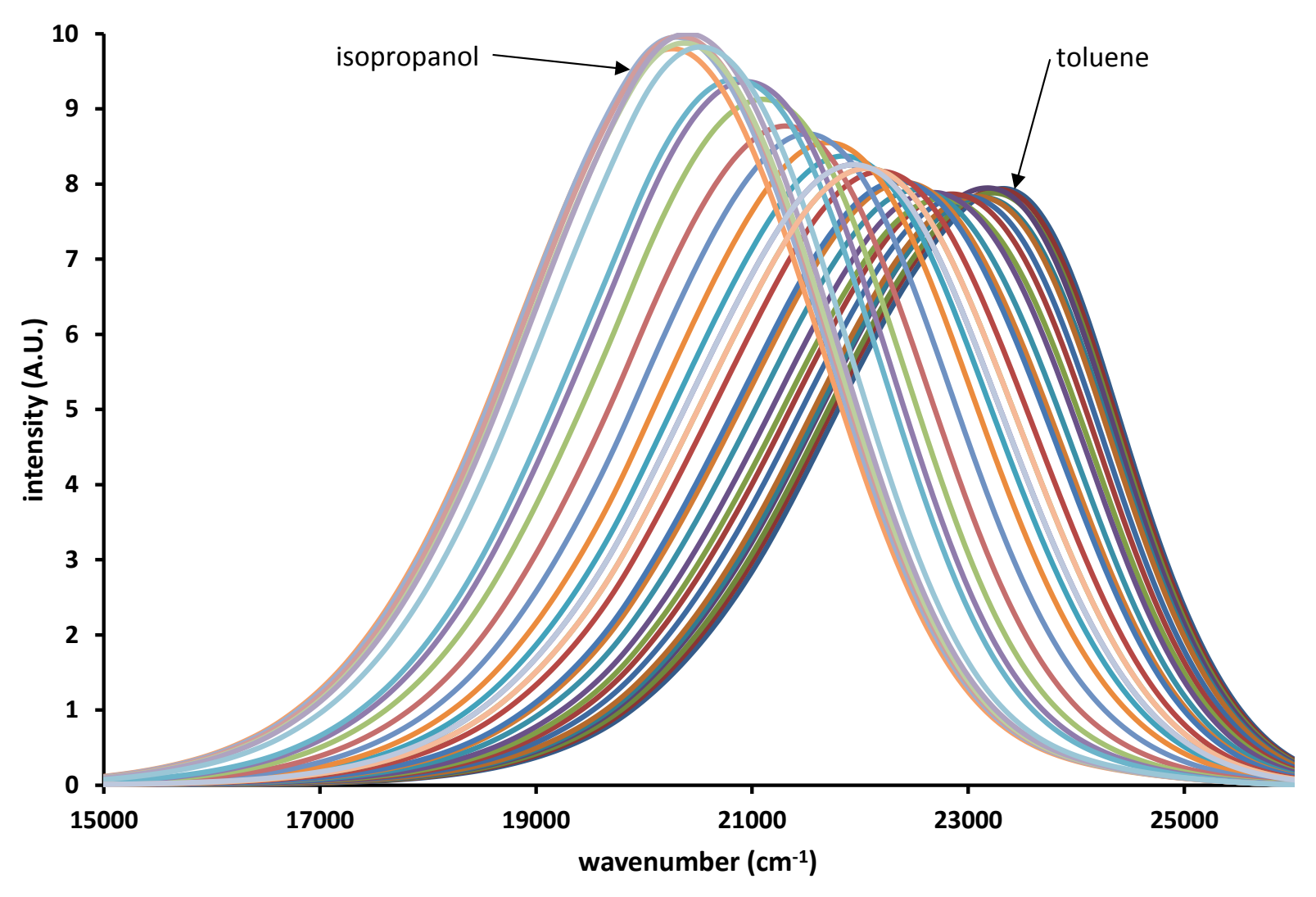

Figure S5. Fluorescence spectra of $9.1 \mu \mathrm{M}$ solutions of 1a in toluene/isopropanol mixtures. $[i \mathrm{PrOH}]($ mole $\%): 0,0.1,0.3,0.4,0.6,0.7,1.0,1.4,1.7,2.0,2.7,3.4,4.0,5.3,7.0,8.0,9.0,12$, $17,26,36,46,53,64,70,78,87,90,93,97,100 . \lambda_{\text {ex }}=366 \mathrm{~nm}$. 


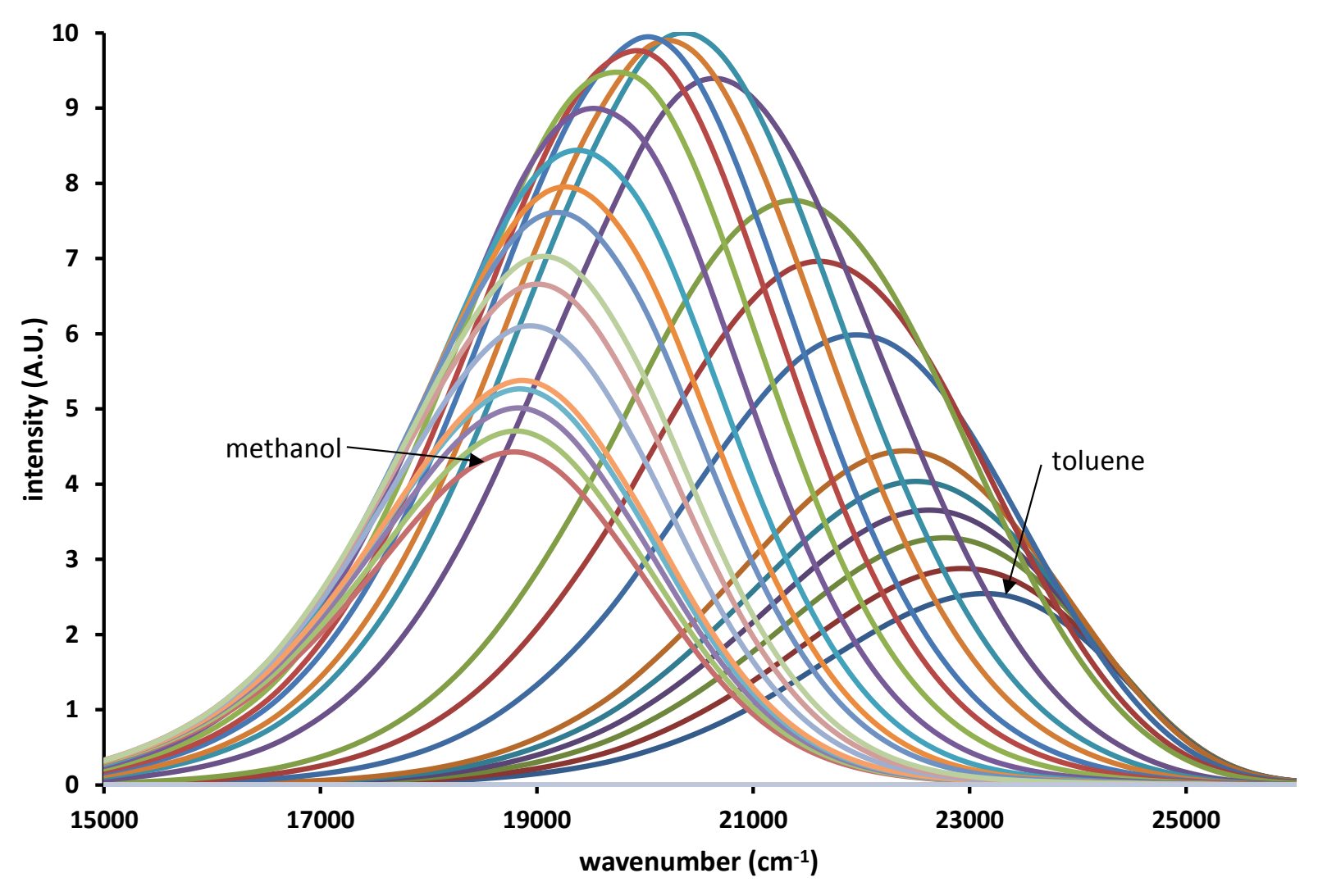

Figure S6. Fluorescence spectra of $4.5 \mu \mathrm{M}$ solutions of $\mathbf{1 b}$ in toluene/methanol mixtures. [MeOH] (mole \%): 0, 0.1, 0.3, 0.4, 0.5, 0.7, 1.3, 1.9, 2.6, 5.6, 8.4, 11, 16, 20, 28, 39, 51, 61, 68, 77, 81, 87, $93,95,96,98,100 . \quad \lambda_{\mathrm{ex}}=366 \mathrm{~nm}$. 


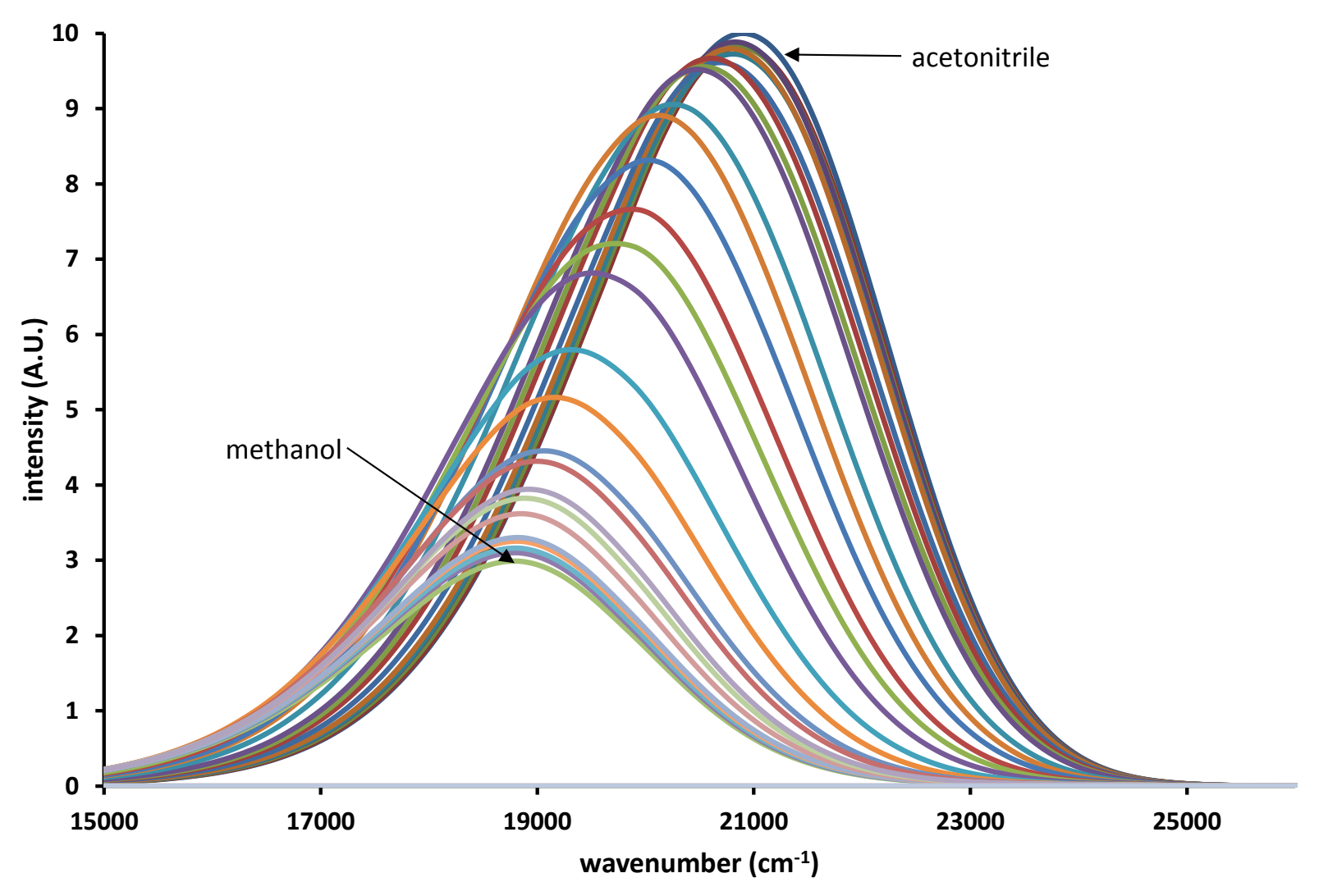

Figure S7. Fluorescence spectra of $4.5 \mu \mathrm{M}$ solutions of $\mathbf{1 b}$ in acetonitrile/methanol mixtures. $[\mathrm{MeOH}]($ mole \%): 0, 0.06, 0.13, 0.19, 0.26, 0.32, 0.64, 1.0, 1.3, 1.6, 3.1, 4.6, 6.1, 8.8, 11, 16, 24 , $34,44,51,62,68,76,87,90,93,96,100 . \lambda_{\mathrm{ex}}=366 \mathrm{~nm}$. 


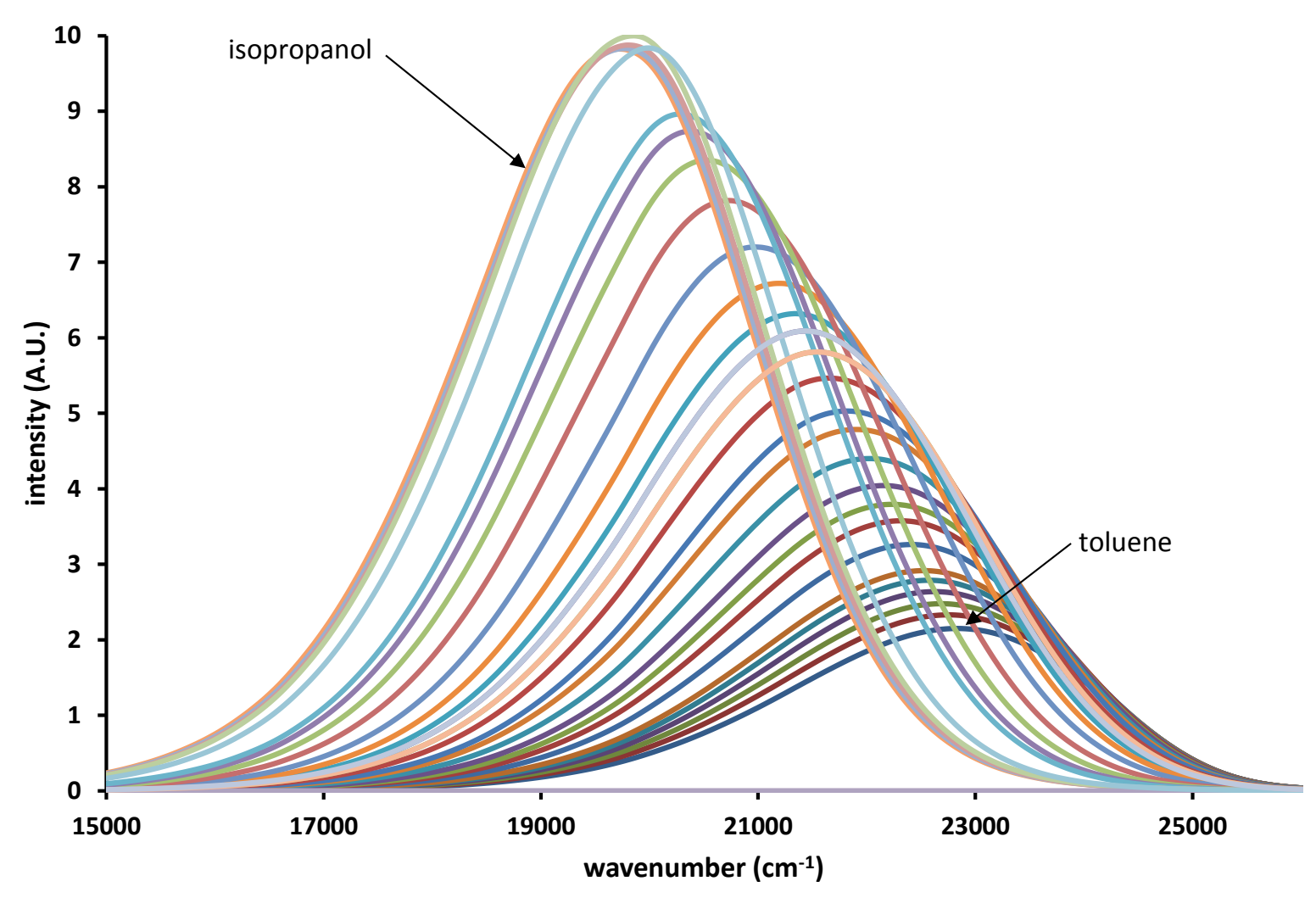

Figure S8. Fluorescence spectra of $4.5 \mu \mathrm{M}$ solutions of $\mathbf{1 b}$ in toluene/isopropanol mixtures. $[i \mathrm{PrOH}](\mathrm{mole} \%): 0,0.1,0.3,0.4,0.6,0.7,1.0,1.4,1.7,2.0,2.7,3.4,4.0,5.3,7.0,8.0,9.0,12$, $17,26,36,46,53,64,70,78,87,90,93,97,100 . \lambda_{\text {ex }}=366 \mathrm{~nm}$. 


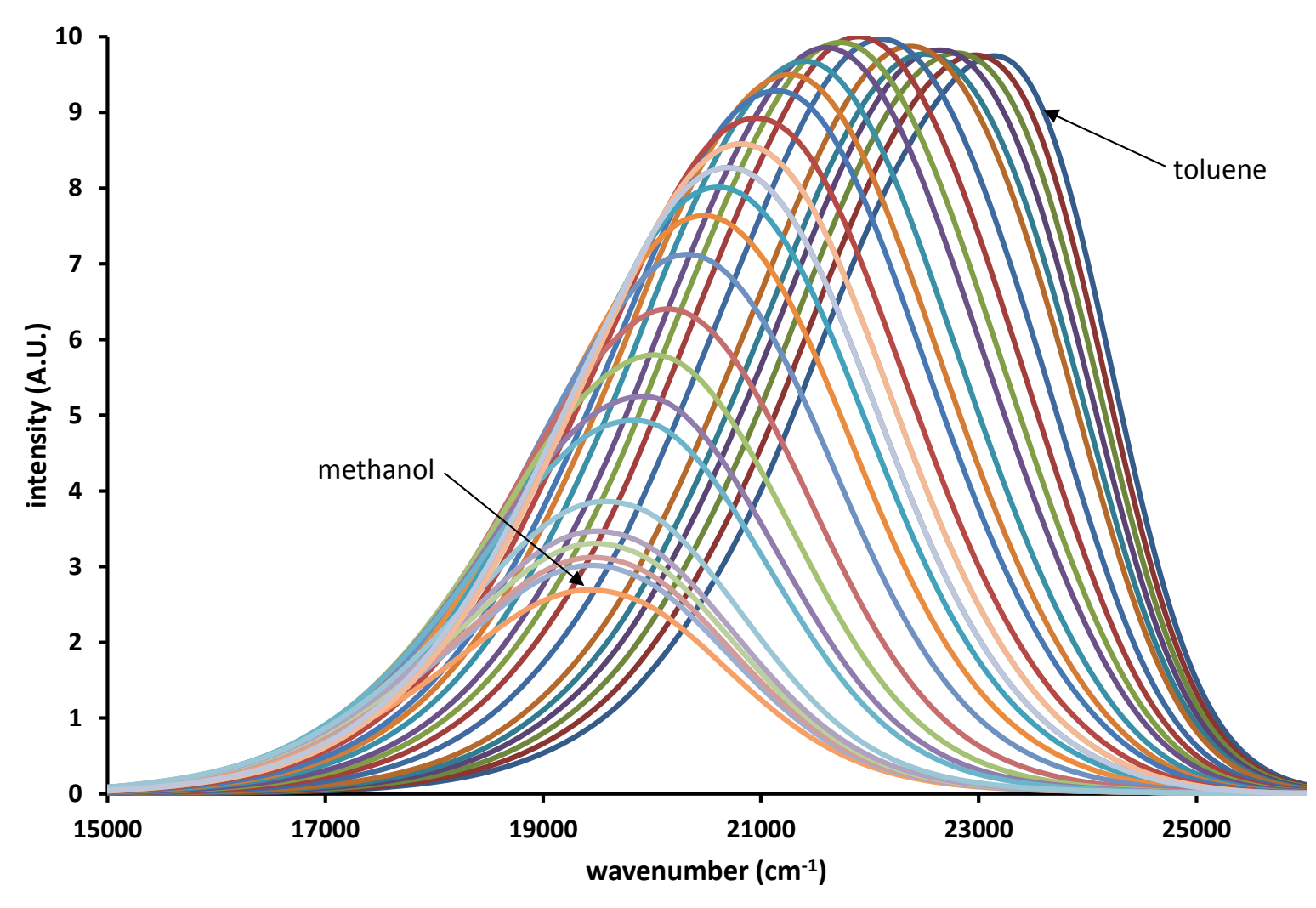

Figure S9. Fluorescence spectra of $7.9 \mu \mathrm{M}$ solutions of $\mathbf{2 a}$ in toluene/methanol mixtures. [MeOH] (mole \%): 0, 0.3, 0.5, 0.8, 1.0, 1.3, 1.9, 2.6, 3.2, 3.8, 5.0, 6.2 , 7.3, 9.5, 12, 14, 16, 21, 28, 40, 51, $61,68,77,81,87,93,95,96,98,100 . \lambda_{\mathrm{ex}}=366 \mathrm{~nm}$. 


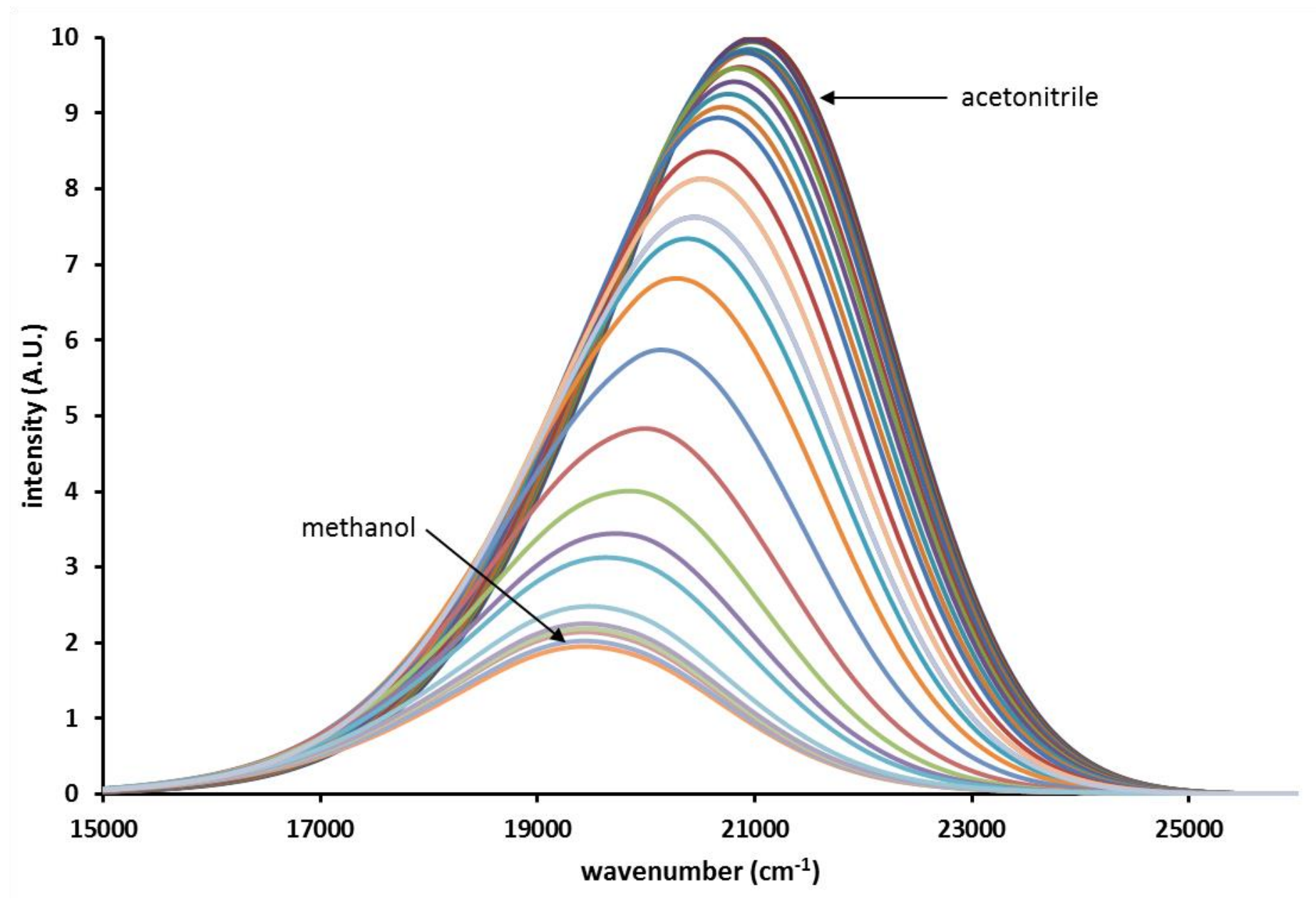

Figure S10. Fluorescence spectra of $7.9 \mu \mathrm{M}$ solutions of $\mathbf{2 a}$ in acetonitrile/methanol mixtures. $[\mathrm{MeOH}]$ (mole \%): 0, 0.1, 0.3, 0.4, 0.5, 0.6, 1.0, 1.3, 1.6, 1.9, 2.5, 3.1, 3.7, 4.9, 6.1, 7.5, 8.8, 11, $16,24,34,44,51,62,68,76,87,90,93,96,100 . \lambda_{\text {ex }}=366 \mathrm{~nm}$. 


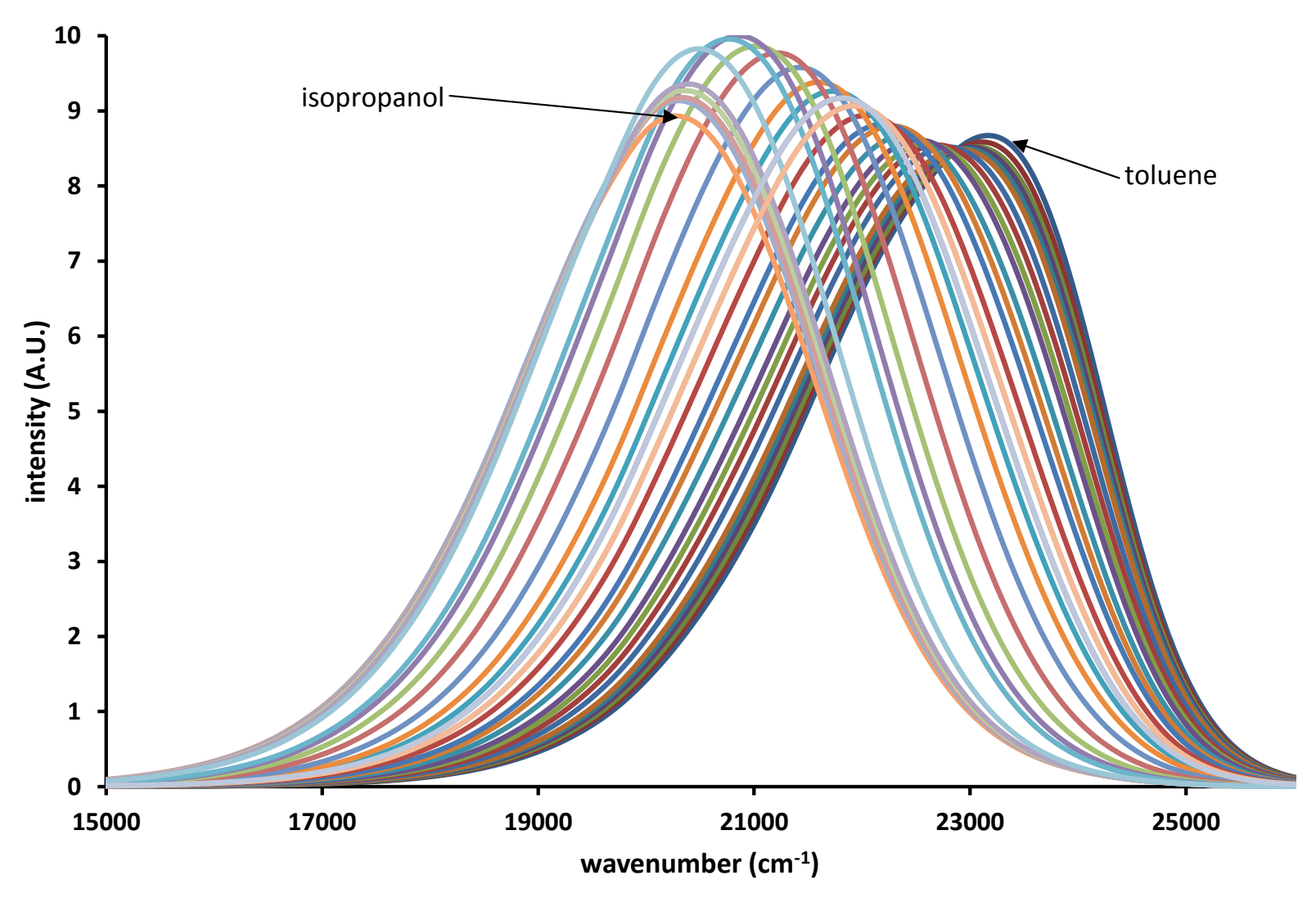

Figure S11. Fluorescence spectra of $7.9 \mu \mathrm{M}$ solutions of 2a in toluene/isopropanol mixtures. [i $\mathrm{PrOH}]$ (mole \%): 0, 0.1, 0.3, 0.4, 0.6, 0.7, 1.0, 1.4, 1.7, 2.0, 2.7, 3.4, 4.0, 5.3, 6.5, 8.0, 9.5, 12, $17,26,36,46,53,64,70,78,87,90,93,97,100 . \lambda_{\mathrm{ex}}=366 \mathrm{~nm}$. 


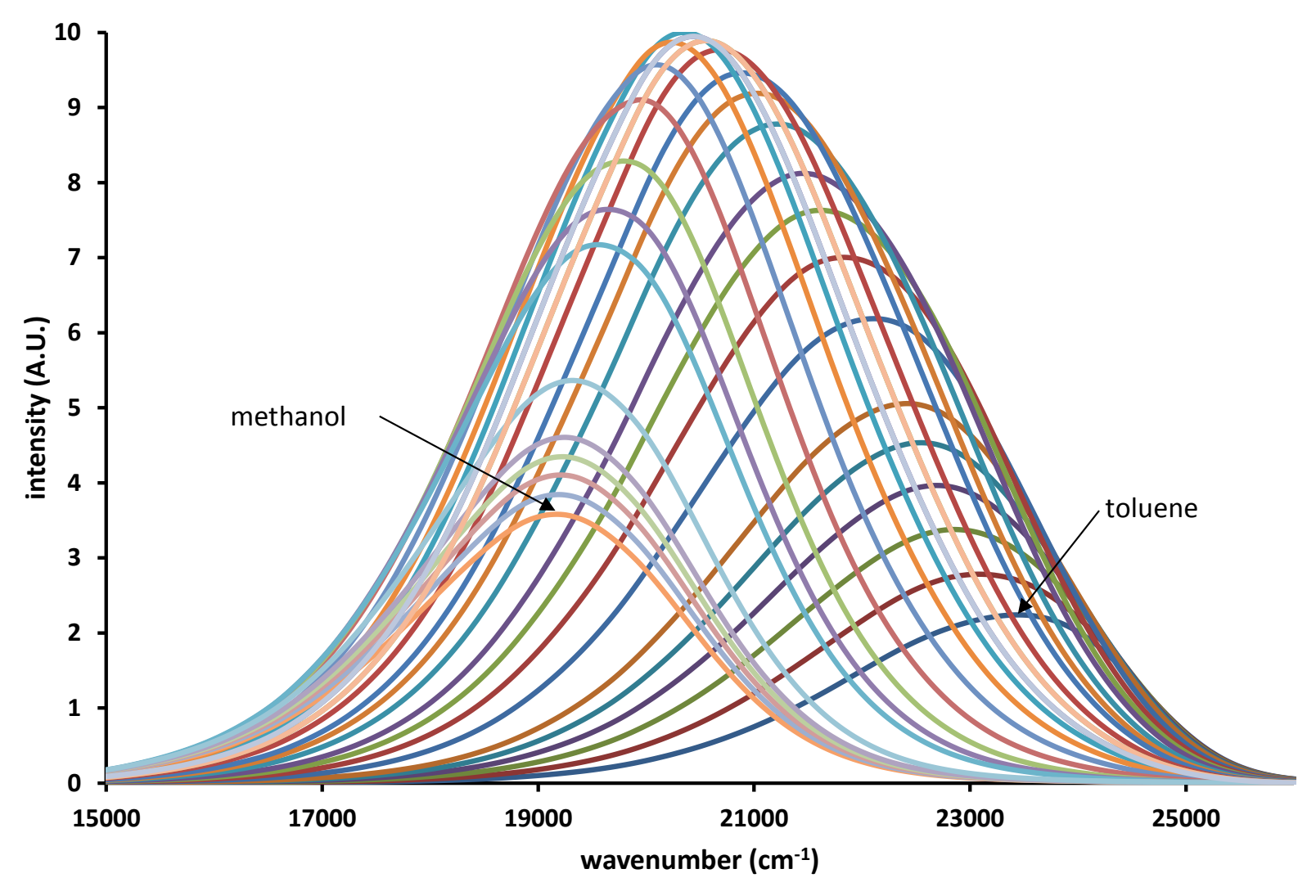

Figure S12. Fluorescence spectra of $14 \mu \mathrm{M}$ solutions of $\mathbf{2 b}$ in toluene/methanol mixtures. $[\mathrm{MeOH}]$ (mole \%): 0, 0.3, 0.5, 0.8, 1.0, 1.3, 1.9, 2.6, 3.2, 3.8, 5.0, 6.2, 7.3, 9.5, 12, 14, 16, 21, 28 , $40,51,61,68,77,81,87,93,95,96,98,100 . \lambda_{\text {ex }}=366 \mathrm{~nm}$. 


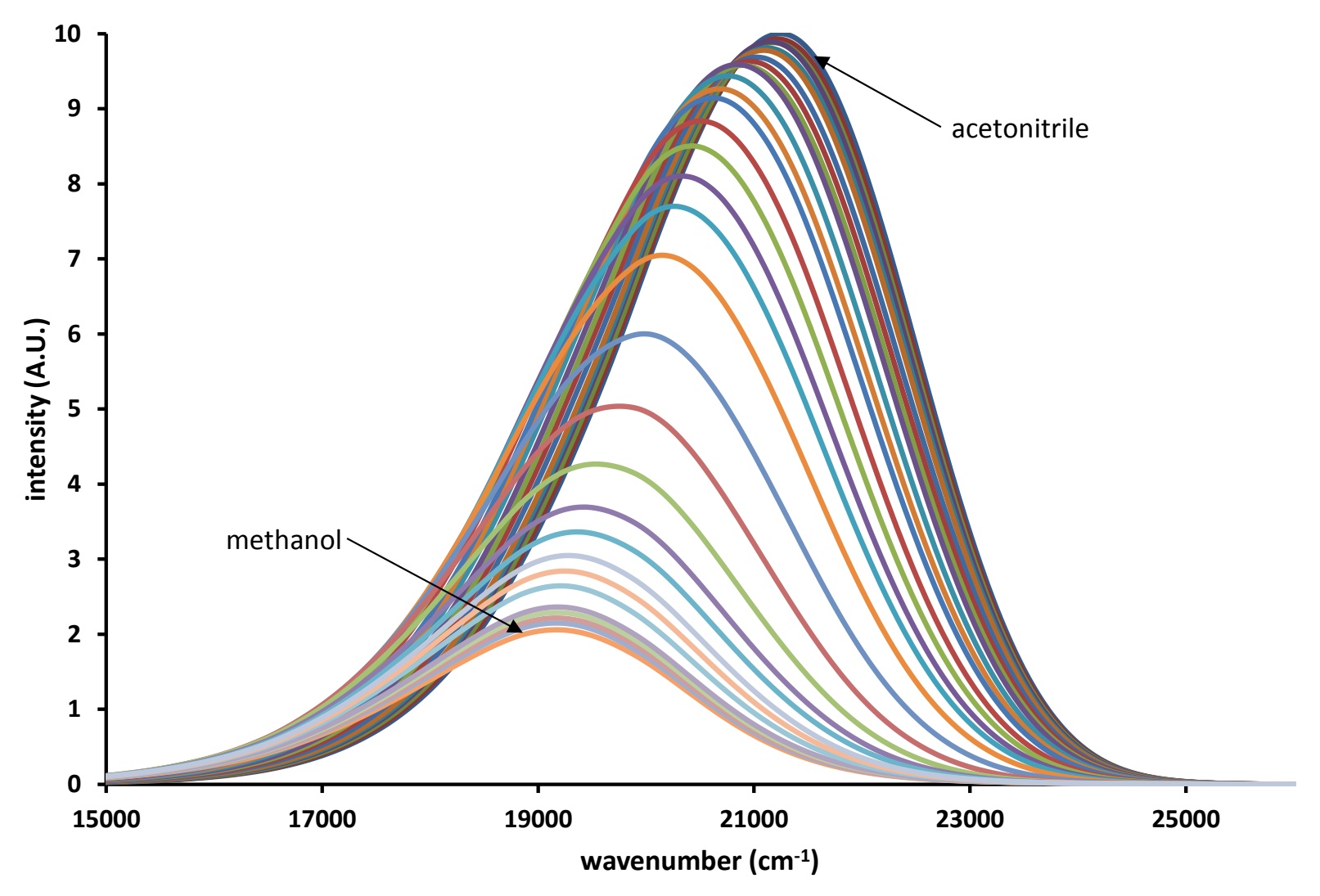

Figure S13. Fluorescence spectra of $14 \mu \mathrm{M}$ solutions of $\mathbf{2 b}$ in acetonitrile/methanol mixtures. $[\mathrm{MeOH}]($ mole $\%): 0,0.1,0.3,0.4,0.5,0.6,1.0,1.3,1.6,1.9,2.5,3.1,3.7,4.9,6.1,7.5,8.8,11$, $16,24,34,44,51,62,68,76,87,90,93,96,100 . \lambda_{\mathrm{ex}}=366 \mathrm{~nm}$. 


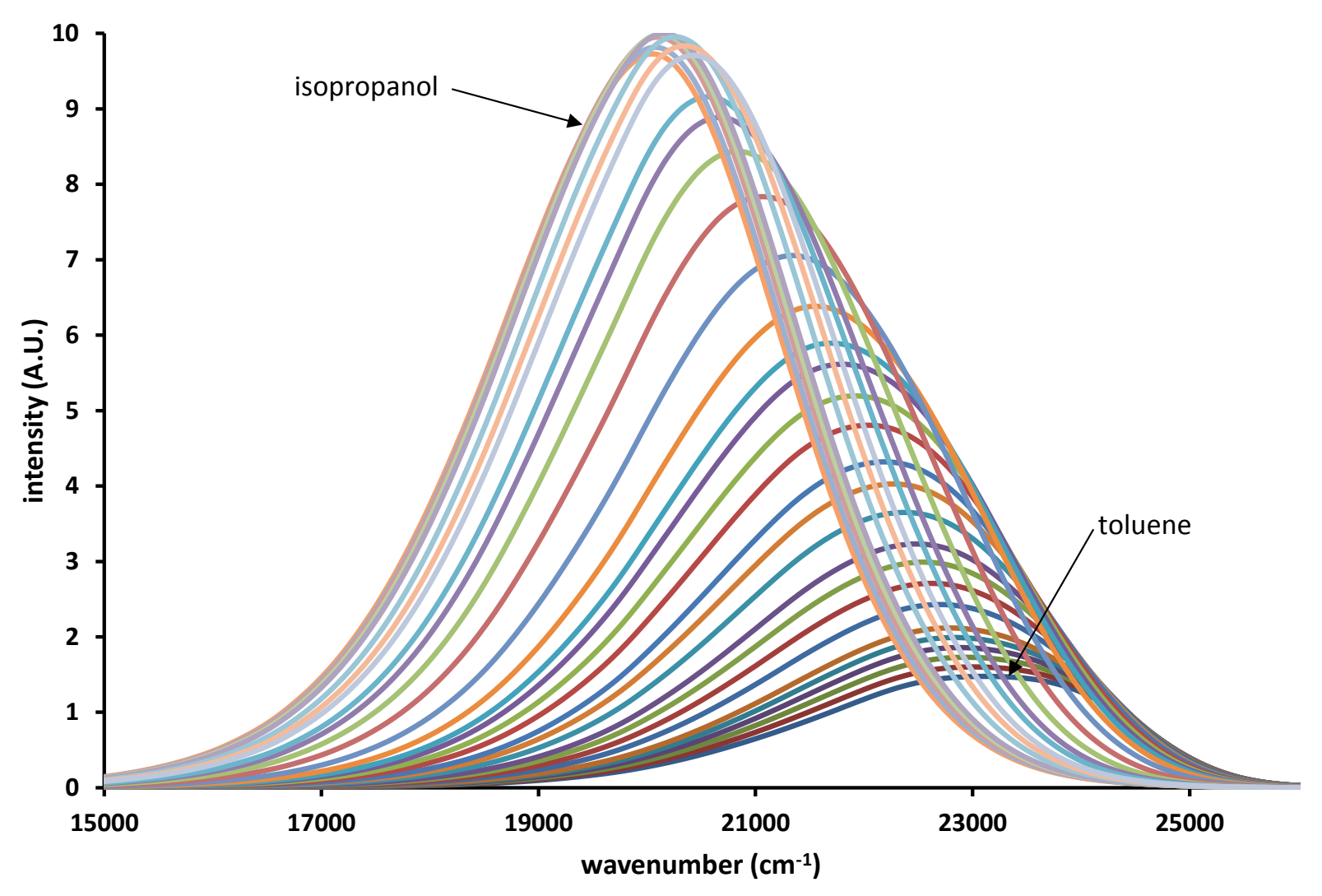

Figure S14. Fluorescence spectra of $14 \mu \mathrm{M}$ solutions of $\mathbf{2 b}$ in toluene/isopropanol mixtures. $[i \mathrm{PrOH}]($ mole \%): 0, 0.1, 0.3, 0.4, 0.6, 0.7, 1.0, 1.4, 1.7, 2.0, 2.7, 3.4, 4.0, 5.3, 6.5, 8.0, 9.5, 12 , $17,26,36,46,53,64,70,78,87,90,93,97,100 . \lambda_{\mathrm{ex}}=366 \mathrm{~nm}$. 


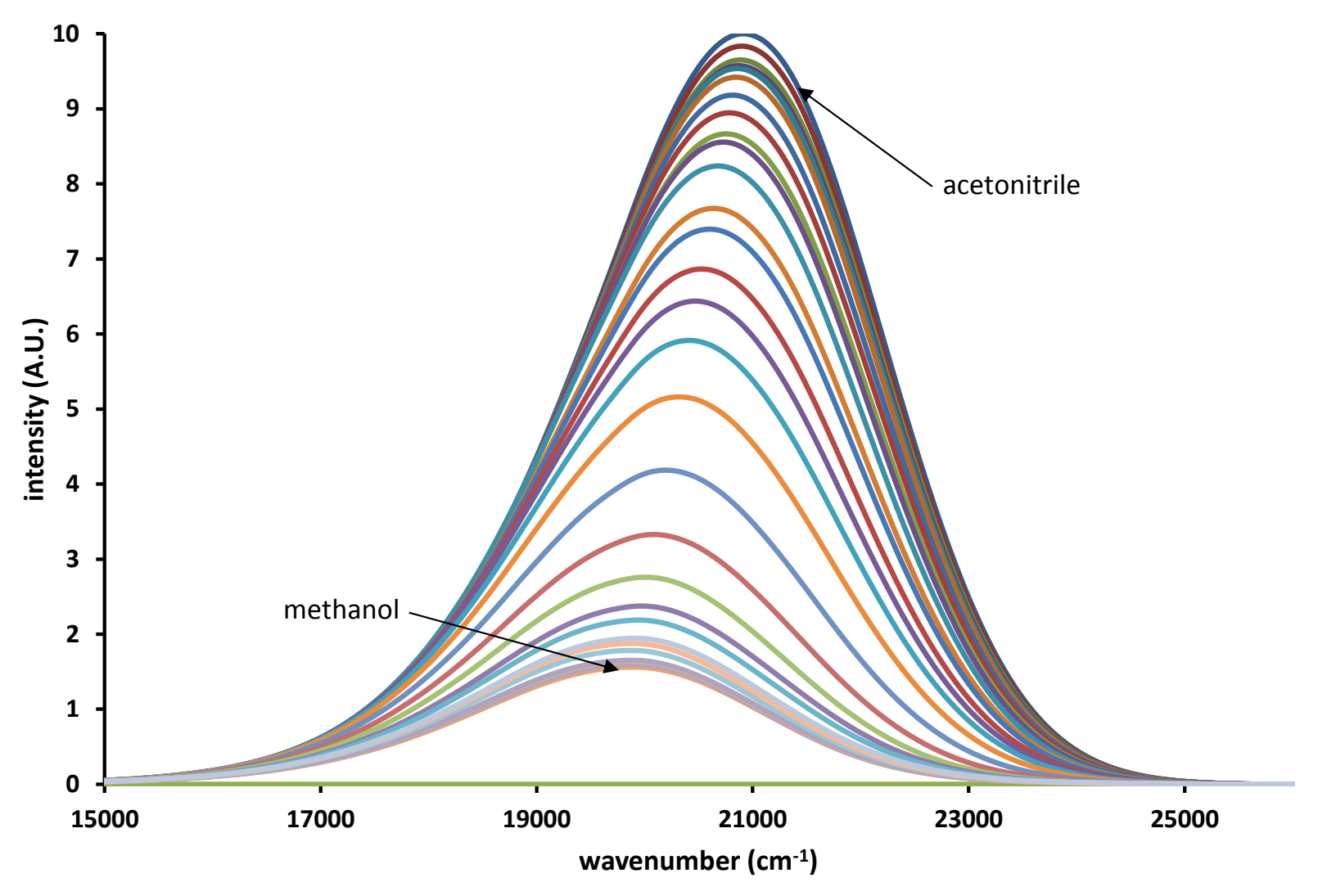

Figure S15. Fluorescence spectra of $9.7 \mu \mathrm{M}$ solutions of $\mathbf{3 a}$ in acetonitrile/methanol mixtures. $[\mathrm{MeOH}]$ (mole \%): 0, 0.1, 0.3, 0.4, 0.5, 0.6, 1.0, 1.3, 1.6, 1.9, 2.5, 3.1, 3.7, 4.9, 6.1, 7.5, 8.8, 11, $16,24,34,44,51,62,68,76,87,90,93,96,100 . \lambda_{\text {ex }}=366 \mathrm{~nm}$. 


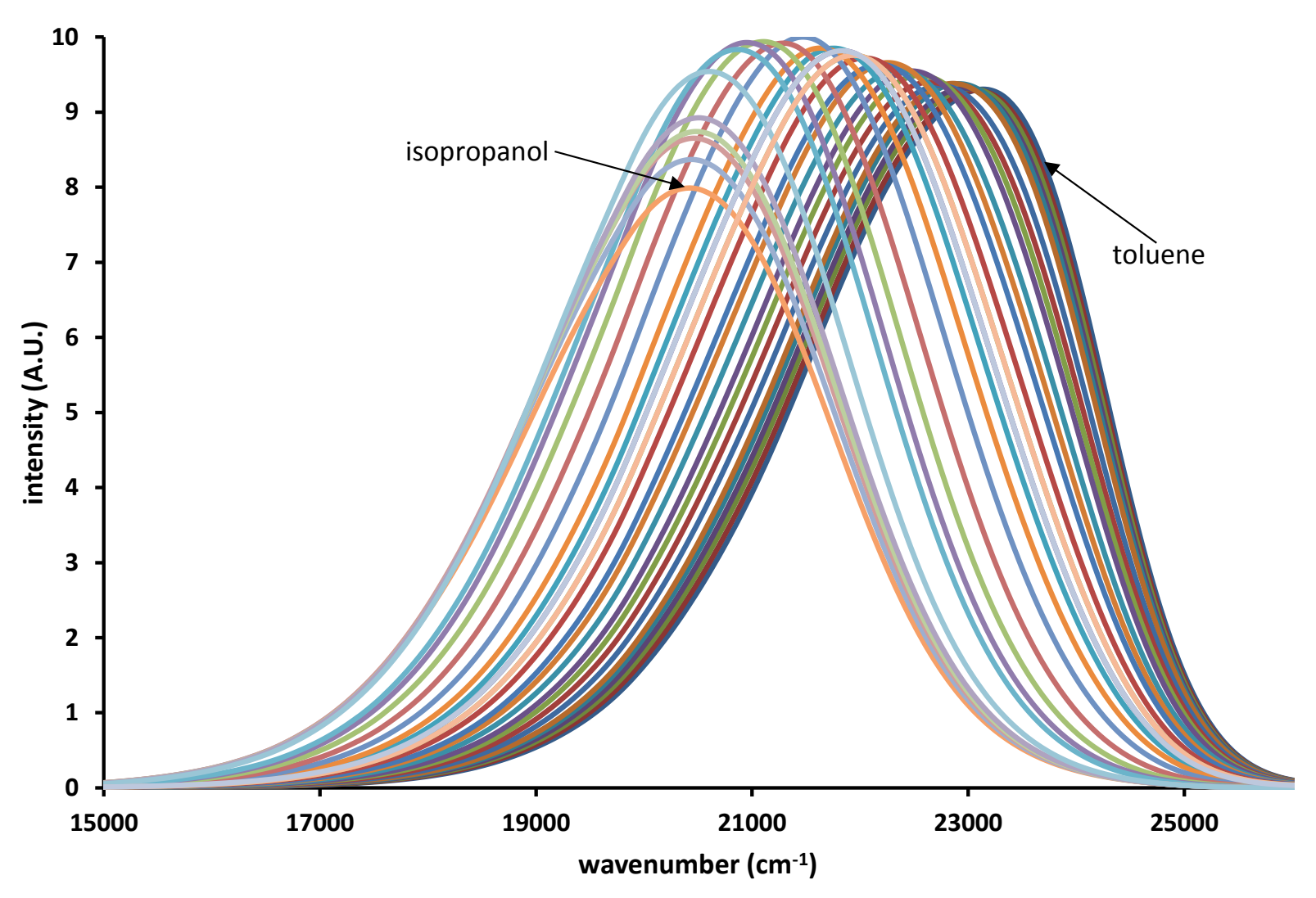

Figure S16. Fluorescence spectra of $9.7 \mu \mathrm{M}$ solutions of 3a in toluene/isopropanol mixtures. [iPrOH] (mole \%): $0,0.1,0.3,0.4,0.6,0.7,1.0,1.4,1.7,2.0,2.7,3.4,4.0,5.3,6.5,8.0,9.5,12$, $17,26,36,46,53,64,70,78,87,90,93,97,100 . \lambda_{\text {ex }}=366 \mathrm{~nm}$. 


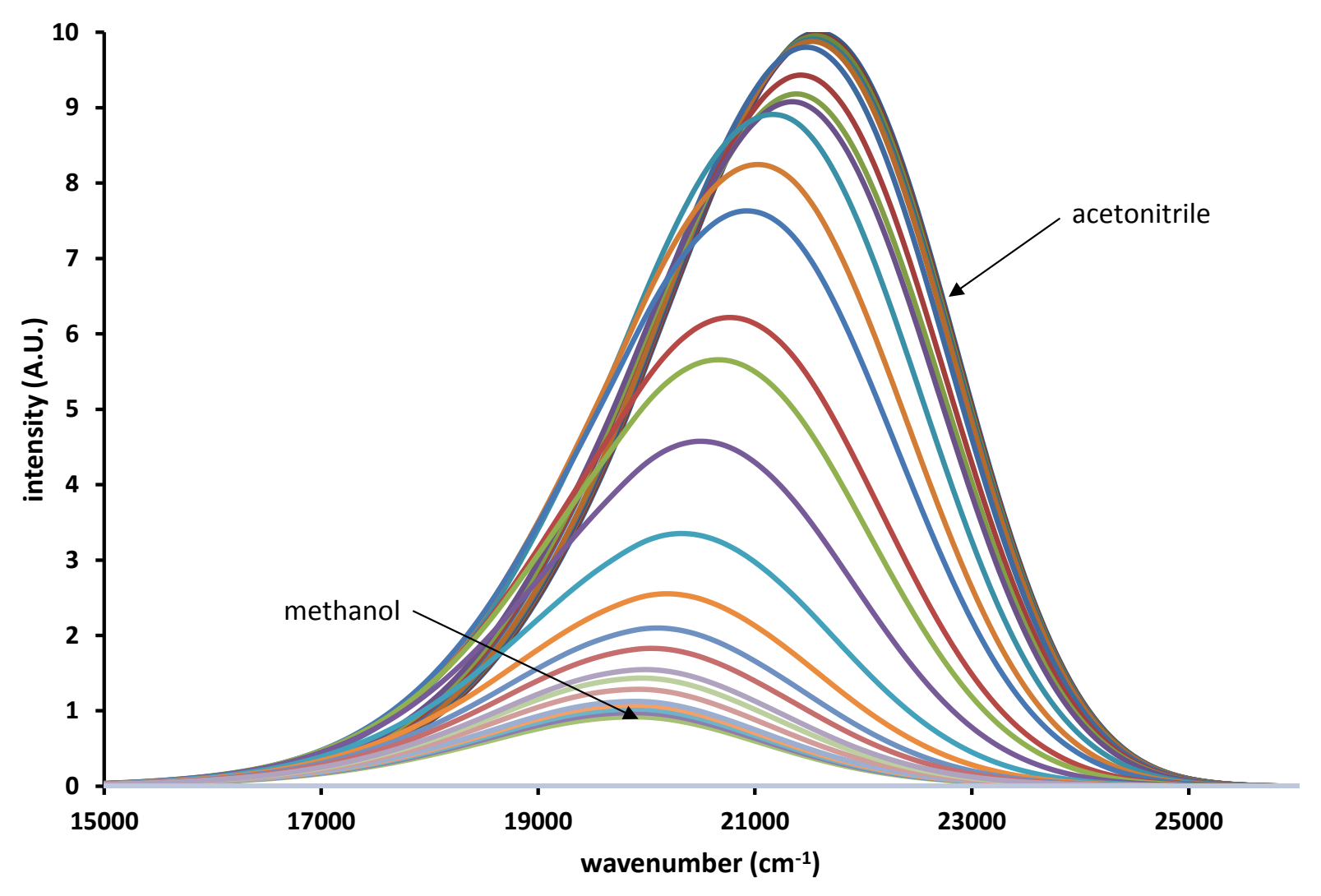

Figure S17. Fluorescence spectra of $9.0 \mu \mathrm{M}$ solutions of $\mathbf{3 b}$ in acetonitrile/methanol mixtures. $[\mathrm{MeOH}]($ mole \%): 0, 0.06, 0.13, 0.19, 0.26, 0.32, 0.64, 1.0, 1.3, 1.6, 3.1, 4.6, 6.1, 8.8, 11, 16, 24, $34,44,51,62,68,76,87,90,93,96,100 . \lambda_{\mathrm{ex}}=366 \mathrm{~nm}$. 


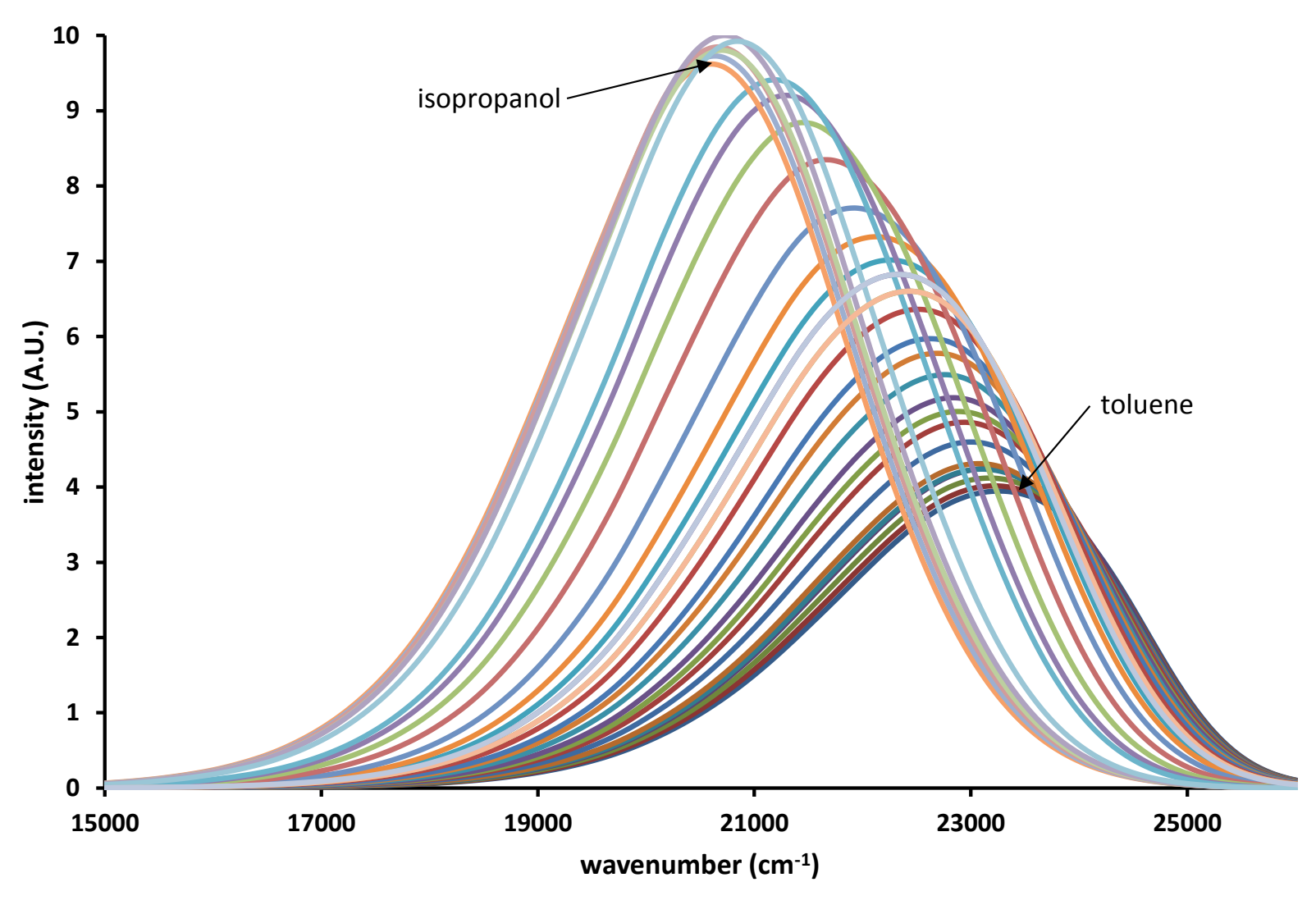

Figure S18. Fluorescence spectra of $9.0 \mu \mathrm{M}$ solutions of $\mathbf{3 b}$ in toluene/isopropanol mixtures. $[i \mathrm{PrOH}]($ mole \%): 0, 0.1, 0.3, 0.4, 0.6, 0.7, 1.0, 1.4, 1.7, 2.0, 2.7, 3.4, 4.0, 5.3, 6.5, 8.0, 9.5, 12 , $17,26,36,46,53,64,70,78,87,90,93,97,100 . \lambda_{\mathrm{ex}}=366 \mathrm{~nm}$. 


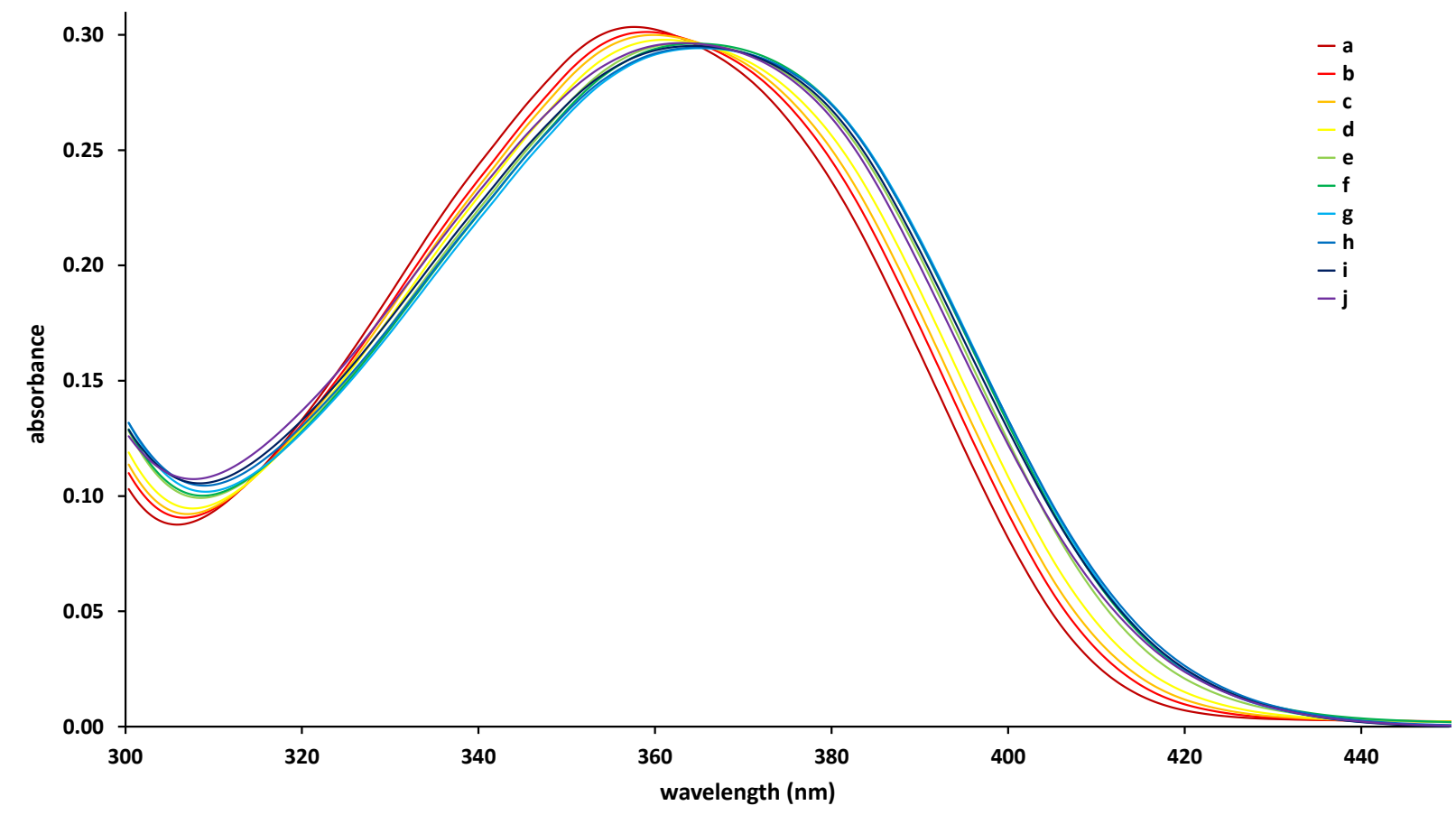

Figure S19. Absorption spectra of $23 \mu \mathrm{M}$ solutions of 1a in toluene/isopropanol mixtures. $[i \mathrm{PrOH}]($ mole \%, a-j): 0.00, 0.05, 0.10, 0.20, 0.40, 0.53, 0.64, 0.80, 0.90, 1.00 .

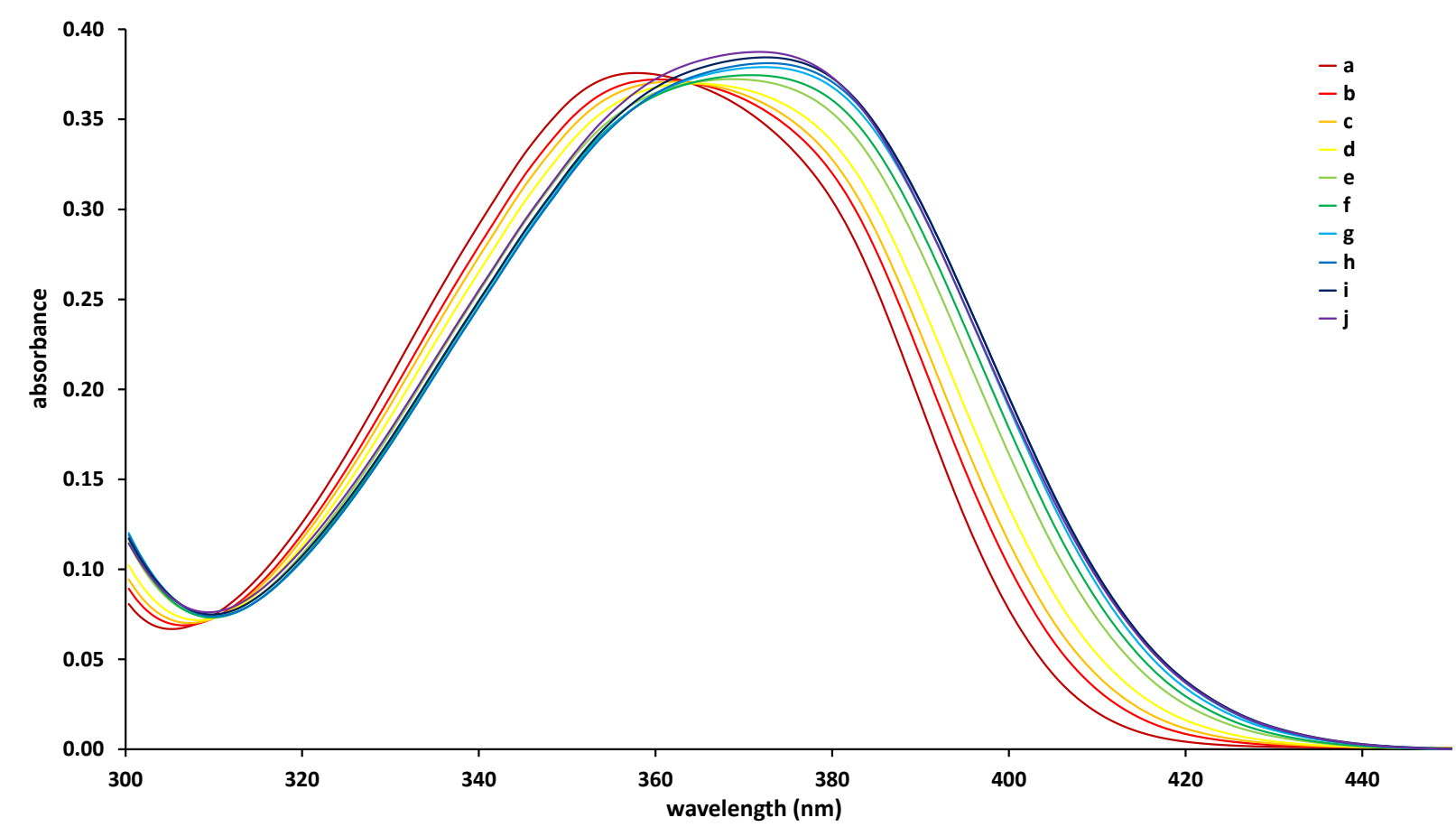

Figure S20. Absorption spectra of $15 \mu \mathrm{M}$ solutions of $\mathbf{1 b}$ in toluene/isopropanol mixtures. $[i \mathrm{PrOH}](\mathrm{mole} \%, \mathrm{a}-\mathrm{j}): 0.00,0.05,0.10,0.20,0.40,0.53,0.64,0.80,0.90,1.00$. 


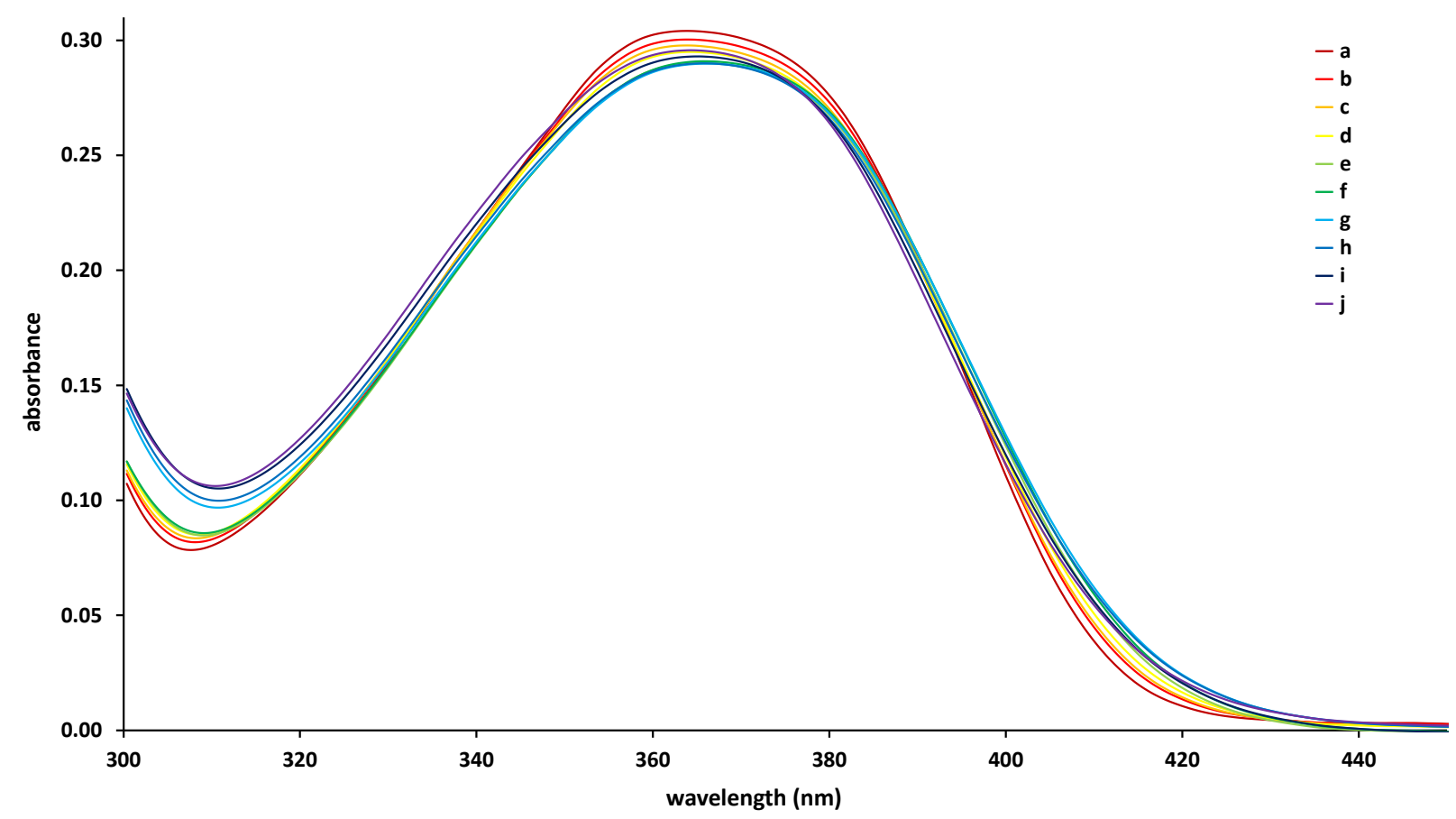

Figure S21. Absorption spectra of $20 \mu \mathrm{M}$ solutions of $\mathbf{2 a}$ in toluene/isopropanol mixtures. $[i \mathrm{PrOH}]($ mole \%, a-j): 0.00, 0.05, 0.10, 0.20, 0.40, 0.53, 0.64, 0.80, 0.90, 1.00 .

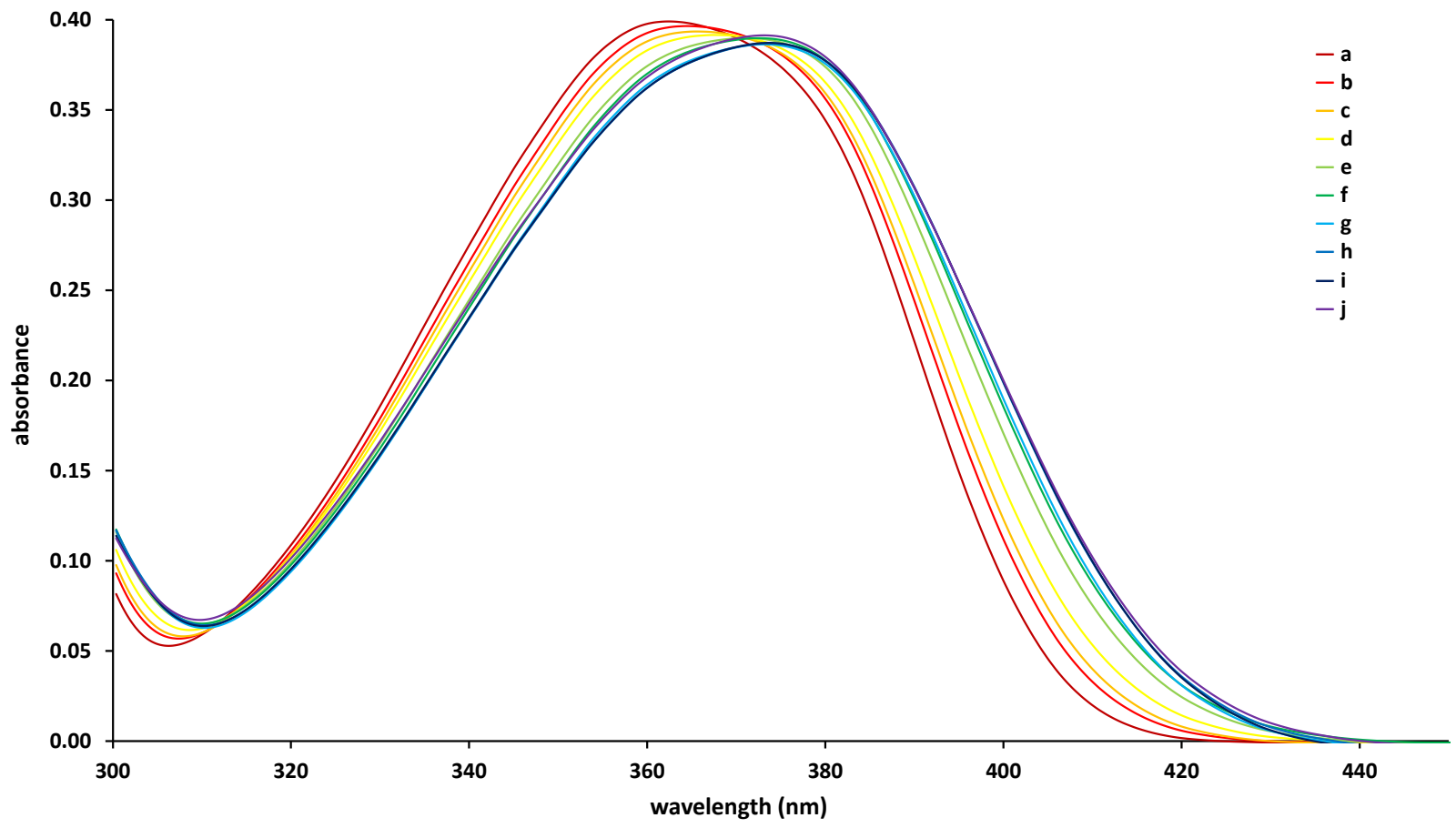

Figure S22. Absorption spectra of $23 \mu \mathrm{M}$ solutions of $\mathbf{2 b}$ in toluene/isopropanol mixtures. $[i \mathrm{PrOH}]($ mole \%, a-j): 0.00, 0.05, 0.10, 0.20, 0.40, 0.53, 0.64, 0.80, 0.90, 1.00 . 


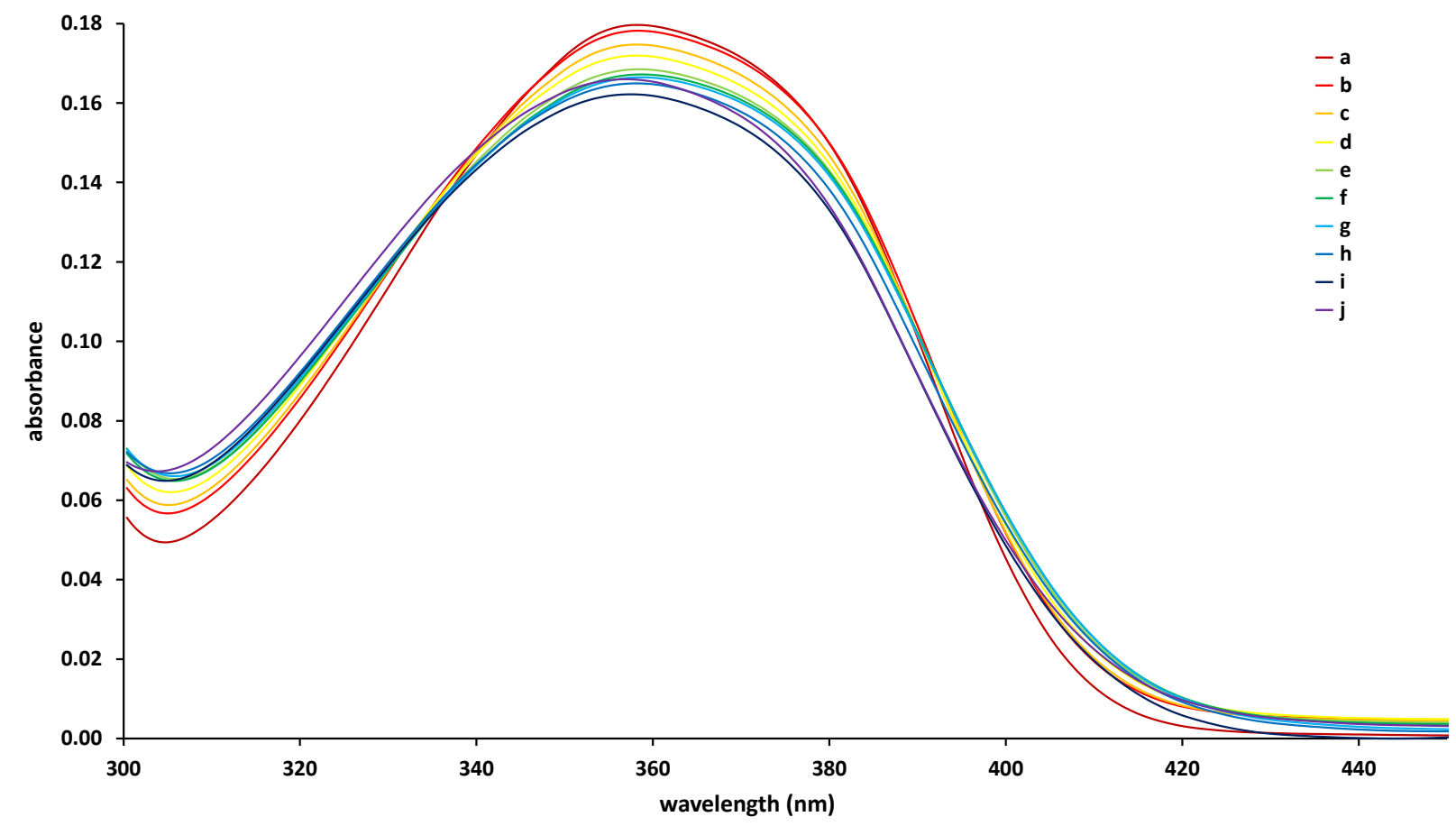

Figure S23. Absorption spectra of $24 \mu \mathrm{M}$ solutions of 3a in toluene/isopropanol mixtures. $[i \mathrm{PrOH}]($ mole \%, a-j): 0.00, 0.05, 0.10, 0.20, 0.40, 0.53, 0.64, 0.80, 0.90, 1.00 .

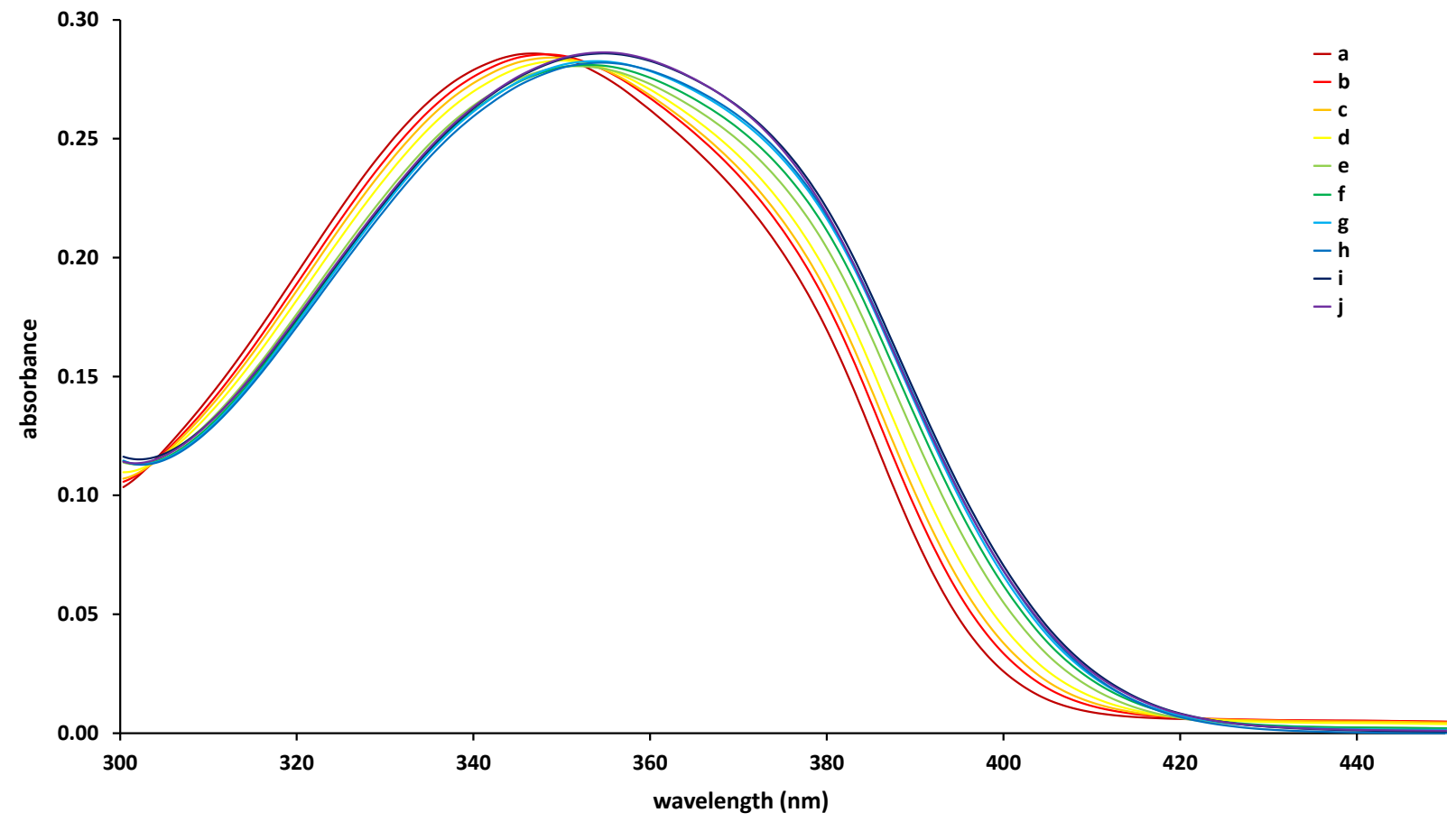

Figure S24. Absorption spectra of $22 \mu \mathrm{M}$ solutions of $\mathbf{3 b}$ in toluene/isopropanol mixtures. $[i \mathrm{PrOH}]($ mole \%, a-j): 0.00, 0.05, 0.10, 0.20, 0.40, 0.53, 0.64, 0.80, 0.90, 1.00 